\title{
Interannual Variability of Northern Hemisphere Storm Tracks in Coarse-Gridded Datasets
}

\author{
Timothy Paul Eichler ${ }^{1}$ and Jon Gottschalck ${ }^{2}$ \\ ${ }^{1}$ Department of Earth and Atmospheric Sciences, Saint Louis University, 3642 Lindell Boulevard, \\ O’Neil Hall 205, St. Louis, MO 63108, USA \\ ${ }^{2}$ NOAA's National Weather Service, National Centers for Environmental Prediction, Climate Prediction Center, \\ 5830 University Research Court, College Park, MD 20740, USA
}

Correspondence should be addressed to Timothy Paul Eichler; teichler@slu.edu

Received 20 August 2013; Revised 22 October 2013; Accepted 12 November 2013

Academic Editor: Igor I. Mokhov

Copyright (C) 2013 T. P. Eichler and J. Gottschalck. This is an open access article distributed under the Creative Commons Attribution License, which permits unrestricted use, distribution, and reproduction in any medium, provided the original work is properly cited.

\begin{abstract}
Extratropical cyclones exert a large socioeconomic impact. It is therefore important to assess their interannual variability. We generate cyclone tracks from the National Center for Environmental Prediction's Reanalysis I and the European Centre for Medium Range Prediction ERA-40 reanalysis datasets. To investigate the interannual variability of cyclone tracks, we compare the effects of El Niño, the North Atlantic Oscillation (NAO), the Indian Ocean Dipole (IOD), and the Pacific North American Pattern (PNA) on cyclone tracks. Composite analysis shows similar results for the impacts of El Niño, NAO, and the PNA on NH storm tracks. Although it is encouraging, we also found regional differences when comparing reanalysis datasets. The results for the IOD suggested a wave-like alteration of cyclone frequency across the northern US/Canada possibly related to Rossby wave propagation. Partial correlation demonstrates that although El Niño affects cyclone frequency in the North Pacific and along the US east coast, its impact on the North Pacific is accomplished via the PNA. Similarly, the PNA's impact on US east coast storms is modulated via El Niño. In contrast, the impacts of the NAO extend as far west as the North Pacific and are not influenced by either the PNA or El Niño.
\end{abstract}

\section{Introduction}

A key issue in assessing present and future climate is in examining the climatology, variability, and trends in the characteristics of extratropical cyclones. The history of cyclone tracks research has two preferred methods to define cyclones. The first is the Eulerian method, which uses band-passed $500 \mathrm{hPa}$ height field and strongest wave activity to define a cyclone (Blackmon [1], Blackmon et al. [2], Wallace et al. [3]), Hoskins and Valdes [4], Chang and Fu [5], Chang [6], Rao et al. [7], C. S. Frederiksen and J. S. Frederiksen [8], and Nakamura and Shimpo [9]). In contrast, a Lagrangian approach tracks cyclones by utilizing diagnostics such as minimum sea-level pressure (MSLP) (Petterson [10], Klein [11], Mather et al. [12], Reitan [13], Zishka and Smith [14], Sanders and Gyakum [15], Whittaker and Horn [16], Lambert [17], Murray and Simmonds [18], Chen et al. [19], Hirsch et al. [20], Eichler and Higgins [21], Changnon et al. [22], and Tilinina et al. [23]) or $850 \mathrm{hPa}$ vorticity (Hodges [24-27], Hoskins et al. [28], Mesquita et al. [29], and Hodges et al. [30]).

Advantages and disadvantages of cyclone methodologies depend on the application of the research. For example, Hodges et al. [30] note that $850 \mathrm{hPa}$ vorticity becomes quite noisy at high-resolution requiring a reduction in spatial resolution. On the other hand, tracking $850 \mathrm{hPa}$ vorticity as opposed to MSLP captures more systems, especially weaker ones (e.g., Hoskins et al. [28] and Hodges et al. [30]). The ability for higher-resolution reanalysis datasets to capture weaker cyclones was also discussed by Tilinina et al. [23], who compared storm track frequency among several reanalysis datasets. Tilinina et al. [23] found that the highresolution NASA MERRA data produced the greatest number of cyclones, with much of the increase due to the inclusion of more shallow cyclones relative to the coarse-gridded 
reanalysis datasets. With regard to intensity, Akperov and Mokhov [31] found that ERA-INTERIM data produced more intense cyclones than ERA-40 or NCEP/NCAR reanalysis data. They also found that ERA-INTERIM produced more smaller $(<200 \mathrm{Km})$ cyclones than ERA-40 and NCEP/NCAR reanalysis data, because of the higher spatial resolution of ERA-INTERIM data. Akperov and Mokhov [31] also illustrate the potential issues of choosing a tracking methodology, as they found that when comparing three different storm tracking routines, the routine developed by Serreze [32] produced less storms than two other routines. Neu et al. [33] compared cyclone tracks over a number of methodologies and found that there was better agreement with regard to deep cyclones, with less agreement for weaker cyclones. With regard to the total number of cyclones, Neu et al. [33] also found qualitative agreement in terms of patterns, although there were large differences when comparing the total number of cyclones. Perhaps the best summary of which cyclone track methodology to use was stated by Mesquita et al. [34] who quoted Leonard et al. [35]: "In carrying out an intercomparison of depression tracking schemes great care must be taken not to draw the misleading conclusions about the merits and values of a particular scheme, since different users of the software will have different requirements."

Although comparisons of cyclone track climatologies among reanalysis datasets are detailed in the literature, less has been done regarding interannual variability. The impact of factors such as El Niño on cyclone tracks is determined by its ability to alter the jet stream. For example, the Pacific North-American Pattern (PNA) described by Wallace and Gutzler [36] was found to be linked to El Niño by Horel and Wallace [37]. Eichler and Higgins [21], Hirsch et al. [20], and Noel and Changnon [38] found an increase in the frequency of $\mathrm{NH}$ winter cyclones along the US east coast during El Niño and a decrease along the US southeast coast during La Niña, which correspond to the positive and negative phase of the PNA, respectively. Gulev et al. [39] stated that cyclone frequency over the Gulf of Mexico and the US east coast was maintained by the North Atlantic Oscillation (NAO) from 1958 to 1978 and the PNA from 1979 to 1999.

Alterations in jet stream strength and location are also linked to the North Atlantic Oscillation (NAO), which refers to fluctuations in sea-level pressure (SLP) between Iceland and the Azores described by Hurrell [40] and Hurrell et al. [41]. An example of NAO impact on cyclone tracks is provided by Bradbury et al. [42], who examined regional effects of the NAO on New England and found a decrease in cyclone frequency in northwestern New England during the negative NAO phase.

In addition to ENSO, the PNA, and the NAO, fluctuations in SST variations in the tropical Indian Ocean have also been linked to global teleconnections. The Indian Ocean Dipole (IOD) refers to SST fluctuations between the eastern and western tropical Indian Ocean first described by Saji et al. [43]. The IOD has been found to be linked to teleconnections, especially in the Southern Hemisphere (e.g., Ashok et al. [44], $\mathrm{Na}$ et al. [45], Ashok et al. [46], and Liu et al. [47]). Global teleconnections have been described in Saji and Yamagata [48], Yamagata et al. [49], and Yang et al. [50]. For the NH, Saji and Yamagata [48] found that the teleconnections in several areas were in opposite phase to ENSO. Interestingly, Annamalai and Okajima [51] found a negative PNA response in the ECHAM5 model in response to Indian Ocean warming. Min et al. [52] suggested that a Rossby wave train propagates from northeast of India to Canada in response to SST changes linked to the IOD.

Given various assimilation systems, satellite data implementation, and instrument errors, it is somewhat surprising that Dee et al. [53] stated that few comparisons have been made between the various datasets. Therefore, this study compares the interannual variability of $\mathrm{NH}$ cyclone tracks in the Reanalysis I and ERA-40 between coarse-gridded reanalysis datasets. Although future work will focus on highresolution datasets such as the CFS reanalysis and JRA25 datasets, we feel it is prudent to first assess the coarse-gridded datasets because of the following. (a) We are examining storm track features compatible with spatial gridding of the reanalysis datasets. (b) The coarse-gridded datasets currently have a longer temporal range than the high-resolution datasets (e.g., the Reanalysis I dataset extends back to 1950 while the CFS reanalysis dataset extends back to 1979) making them highly suitable for interannual variability studies. (c) Although there are many studies of storm track climatology, there are less studies on their interannual variability; this is especially true when comparing interannual variability between different reanalysis datasets. (d) Examination of the interannual variability of storm tracks in coarse-gridded datasets will provide a foundation for comparing to higherresolution datasets. The organization of our paper is as follows. Section 2 describes the methodology for generating cyclone tracks, developing cyclone track frequency and intensity climatologies, and analyzing interannual variability. Section 3 explores differences in interannual variability as a function of ENSO, NAO, PNA, and the IOD via composite analysis and partial correlation. In Section 4, we review and discuss our results and present our conclusions.

\section{Methodology}

Cyclone tracks were generated from 6-hourly reanalysis data for Reanalysis I (1950-2010), Reanalysis II (1979-2010), and ERA-40 (1958-2001). To ensure consistency among the comparisons, all of the datasets had identical spatial resolution $\left(2.5^{\circ}\right.$ Lat $\times 2.5^{\circ}$ Lon $)$. To track cyclones, we utilize a Lagrangian approach developed by Serreze [32] and Serreze et al. [54] that determines the minimum sea-level pressure (MSLP) field relative to surrounding grid points to track cyclones. We utilized the same criterion in the cyclone track algorithm as Eichler and Higgins [21] by choosing a one hPa threshold for finding cyclones and a maximum propagation distance of $800 \mathrm{~km}$ between timesteps. Although this is an overestimate of a distance a cyclone can travel between timesteps, it does allow for the possibility of center jumps (e.g., cyclones reforming on the opposite side of a mountain chain) and also accounts for the gridded nature of the data we are using.

Reanalysis datasets used in our assessment include the National Center for Environmental Prediction (NCEP) 
TABLE 1: Cyclone track climatology reanalysis datasets. Note that abbreviations include the beginning and end year of the dataset (e.g., NCEP1_5010 represents Reanalysis I data from 1950 to 2010).

\begin{tabular}{lc}
\hline Dataset & Abbreviation used in study \\
\hline Reanalysis I (1950-2010) & NCEP1_5010 \\
Reanalysis I (1958-2001) & NCEP1_5801 \\
Reanalysis I (1979-2010) & NCEP1_7910 \\
Reanalysis I (1950-1978) & NCEP1_5078 \\
ECMWF reanalysis (1958-2001) & ERA40_5801 \\
\hline
\end{tabular}

Reanalysis I dataset (Kalnay et al. [55]) and the European Center's ERA-40 reanalysis dataset (Uppala et al. [56]). To facilitate comparisons among the various reanalysis products, we subdivided the datasets as shown in Table 1 and described as follows. For NCEP1_5010, we extend the cyclone track analysis done by Eichler and Higgins [21] from 2002 to 2010. We also created a subset of the Reanalysis I dataset from 1958 to 2001 for direct comparison to ERA-40. To assess possible changes in storm tracks due to temporal changes in the coupling strength between ENSO and the NAO (Pinto et al. [57]), or due to an altered temporal response in cyclone frequency as a function of the NAO (Gulev et al. [39]), we created two subsets of NCEP1_5010: one from 1950 to 1978 (NCEP1_5078) and the other from 1979 to 2010 (NCEP1_7910).

Similar to Eichler and Higgins [21], mean, seasonal cyclone track frequencies were generated by binning cyclones into $5^{\circ}$ Lat $\times 5^{\circ}$ Lon boxes for winter (JFM), spring (AMJ), summer (JAS), and fall (OND). To ensure direct comparison with Re27910 and ERA40_5801 data, Reanalysis I climatologies were also tabulated for the period 1979-2010 (NCEP1_7910) and 1958-2001 (NCEP1_5801) to match Re27910 and ERA40_5801 time periods, respectively. Although we do focus on cyclone climatology, the frequency climatologies for each dataset are shown in Appendix A.

Seasonal cyclone intensity was determined with the same methodology used by Eichler and Higgins [21]. First, we generated a gridded cyclone intensity climatology by binning cyclone MSLP. Next, we developed a seasonal MSLP climatology for each reanalysis dataset from monthly mean MSLP data. To eliminate potential errors due to trends, we applied a linear regression to the seasonal mean MSLP climatology. We then normalized our cyclone track intensity climatology by subtracting the seasonal regressed MSLP for the periods 1950-2010 (NCEP1_5010), 1979-2010 (NCEP1_7910), and 1958-2001 (NCEP1_5801 and ERA40_5801). As was the case for storm track frequency climatology, the intensity climatologies for each dataset are shown in Appendix B.

To evaluate the interannual variability of storm track frequency and intensity, we utilized the January through March (JFM) storm track data for each year. The choice of JFM was due to NH cyclone tracks being most influenced by external forcing in winter. However, we also generate October through December (OND) frequency and intensity climatologies, since the Indian Ocean Dipole (IOD) is the strongest during NH autumn [52]. The strongest El Niño and La Niña periods were found by using the ENSO Intensity
TABLE 2: Years used in composite study for El Niño, NAO, and IOD (JFM except OND for IOD).

\begin{tabular}{ll}
\hline El Niño & $\begin{array}{l}1950,1958,1966,1969,1973,1983,1987,1992, \\
1998,2010\end{array}$ \\
\hline La Niña & $1950,1971,1974,1976,1989,1999,2000,2008$ \\
\hline Positive PNA & $1977,1981,1983,1984,1987,2010$ \\
\hline \multirow{2}{*}{ Negative PNA } & $1950,1951,1952,1954,1955,1956,1957,1959$, \\
& $1962,1965,1967,1969,1971,1972,1974,1975$, \\
& $1976,1979,1982,1989,1990,1996,2002,2009$ \\
\hline \multirow{2}{*}{ Positive NAO } & $1950,1957,1959,1961,1967,1973,1974,1976$, \\
& $1983,1989,1990,1992,1993,1994,1995,1997$, \\
\hline Negative NAO & $1998,2000,2002,2008$ \\
\hline
\end{tabular}

Index (EIS) described in Kousky and Higgins [58], which is calculated by doubling the Ocean Niño Index (ONI). To detect impacts from El Niño, we composited cyclone track frequency and intensity for the strongest El Niño and La Niña periods and these are shown in Table 2. To ensure a balance between sample size and using sufficiently strong ENSO events to detect potential signals, we composited moderate/strong El Niño (La Niña) events for EIS greater than or equal (less than or equal) to two (negative two). For the NAO and IOD, we utilized data from Jones et al. [59] and Saji et al. [43], respectively. The PNA Index was obtained from NOAA's Climate Prediction Center (CPC), for which the values were standardized by the 1981-2010 climatology (see http://www.cpc.ncep.noaa.gov/data/teledoc/pna.shtml for more details). Compositing the NAO, PNA, and IOD was done according to standard deviation (SD). Defining a proper cutoff for SD is somewhat arbitrary. For example, Noel and Changnon [38] used 1 SD for compositing ENSO events. Bai et al. [60] used 0.5 SD to define NAO events, while Serreze et al. [54] selected the top positive and bottom negative seven years for NAO and defined NAO phase by quartile. While the methodology used by Serreze et al. [54] is attractive because it ensures an evenly distributed sample size, it does not account for the possibility of the nonsymmetry of positive/negative phases of the NAO (e.g., the positive events may be defined by a higher NAO value relative to the criterion for the negative $\mathrm{NAO}$ ). On the other hand, the $0.5 \mathrm{SD}$ cutoff used by Bai et al. [60] may allow for the inclusion of events that will not give sufficient separation from neutral events. As a compromise, we defined $\mathrm{NAO}, \mathrm{PNA}$, and IOD events by $0.75 \mathrm{SD}$. Although slightly more strict than that used by Bai et al. [60], it still provides an adequate sample size (see Table 2). To assess statistical significance of the composites, we again apply the $t$-score used by Bai et al. [60]. Results are considered significant for a 2 -tailed test criterion of 90 percent.

Finally, we performed a partial correlation analysis to quantify the impacts of El Niño, PNA, and NAO on cyclone track frequency found in the composite analysis. Partial correlation, which is a method to filter out external effects, was used by Ashok et al. [46] for Southern Hemisphere cyclone tracks to eliminate the IOD when determining El Niño relationships and vice versa. For our study, we show 


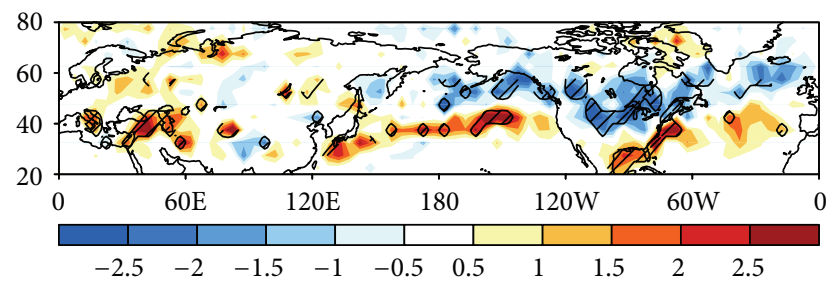

(a)

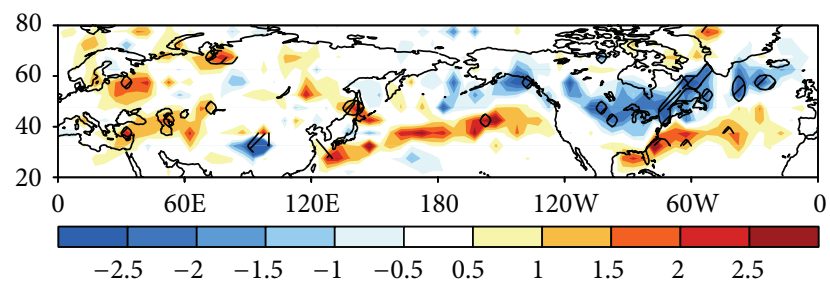

(b)

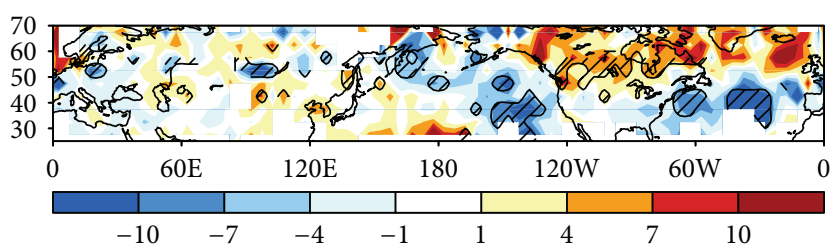

(c)

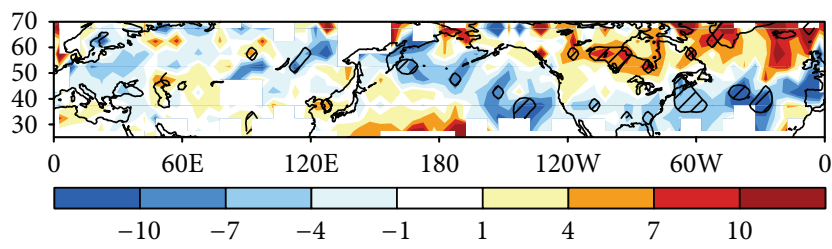

(d)

Figure 1: NH winter (JFM) El Niño-La Niña cyclone track frequency composite for (a) NCEP1_5801, (b) like (a) but for ERA40_5801. Units: no. of cyclones per $5^{\circ}$ Lat $\times 5^{\circ}$ Lon box. Hatched areas are significant at $90 \%$ for 2 -tailed $t$-test. (c) NH winter (JFM) El Niño-La Niña cyclone track intensity composite for NCEP1_5801. (d) like (c) but for ERA40_5801. Units: hPa. Hatched areas are significant at $90 \%$ for 2 -tailed $t$-test.

(1) El Niño correlations eliminating PNA and NAO, (2) PNA eliminating El Niño, and (3) the NAO eliminating PNA and El Niño. Since the IOD was found to have weak correlations, we did not include the IOD in the analysis. Sufficient temporal size allowed us to compare different time periods in the same dataset (i.e., NCEP1_7910 versus NCEP1_5078) in addition to comparing two different reanalysis datasets (i.e., ERA15801 versus NCEP1_5801).

\section{Interannual Variability}

3.1. Composite Analysis. Figure 1 shows cyclone track frequency and intensity composites for El Niño relative to La Niña for NCEP1_5801 and ERA40_5801. Both datasets show significantly more cyclones along the US east coast and extending across the north central Pacific, with significantly less cyclones over the Gulf of Alaska (Figures 1(a) and 1(b)). This pattern suggests a positive (negative) Pacific North American pattern (Wallace and Gutzler [36]), with a southward (northward) displaced cyclone track in the North Pacific with increased (decreased) cyclones along the east coast during El Niño (La Niña). More frequent cyclones are also seen in the eastern Mediterranean and over Italy; the latter being prominent for NCEP1_5801 suggesting that assimilation differences between NCEP reanalysis and ECMWF reanalysis are playing a role (compare Figure 1(a) with Figure 1(b)). Another interesting feature is over the North Atlantic, where there are increased cyclones in the North Atlantic, with less cyclones just south of Greenland (Figures 1(a) and 1(b)). This resembles a negative phase of the $\mathrm{NAO}$ and is consistent with the results found by Rogers [61], who linked the Southern Oscillation (SO) with the NAO. As will be demonstrated when examining partial correlations, this result will be dependent on the time period chosen for the analysis suggesting a nonrobust relationship.

The SLP composites for El Niño relative to La Niña are generally consistent across both datasets, with more intense cyclones in the North Pacific and North Atlantic from $35^{\circ} \mathrm{N}$ to $50^{\circ} \mathrm{N}$ and less intense cyclones across much of Canada and the North Atlantic from $60^{\circ} \mathrm{N}$ to $70^{\circ} \mathrm{N}$ (Figures $1(\mathrm{c})$ and $1(\mathrm{~d})$ ). The increase in intensity in the North Pacific is consistent with a stronger Aleutian low occurring during El Niño, while the increased intensity of cyclones along the US east coast is consistent with an enhanced east coast cyclone track during El Niño consistent with the results of Eichler and Higgins [21]. The decrease in cyclone intensity across Canada during La Niña relative to El Niño is indicative of a northwarddisplaced polar jet during La Niña. As was the case for the El Niño frequency composite, the decrease (increase) in cyclone intensity south of Greenland (across the mid-North Atlantic) resembles the negative phase of the NAO (Rogers [61]).

For the NAO (Figure 2), the most notable impact is the frequency dipole in the Atlantic suggesting that more (less) frequent cyclones occur south of Greenland, with less (more) cyclones west of Europe consistent with a northward (southward) displacement of the cyclone track during positive (negative) NAO (Figures 2(a) and 2(b)). This agrees with Luo et al. [62], who compared North Atlantic cyclone tracks during a period when the NAO was trending upward (1978-1990) with a period when the NAO was trending downward (19912009) and concluded that the North Atlantic cyclone track was more intense when the NAO was trending downward. Our results are also consistent with Walter and Graf [63], who examined teleconnection patterns related to the strength of the polar vortex and found that, when the vortex was strong, cyclone tracks extend northward into the Arctic Ocean, with a secondary track over the Denmark Strait.

An interesting feature in our NAO composite is that it is not confined strictly to the NAO centers of action in the North Atlantic (Figures 2(a) and 2(b)). For example, the positive area south of Greenland extends west-southwestward to Central Canada, while the negative area in the North Atlantic extends eastward through the Mediterranean. A significant increase in cyclones during $\mathrm{NAO}$ positive relative to $\mathrm{NAO}$ 


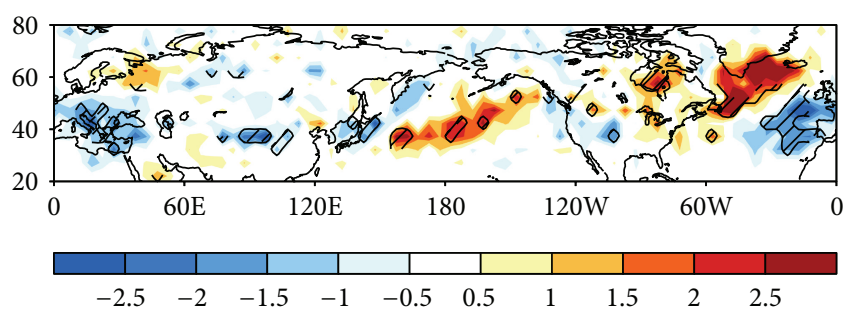

(a)

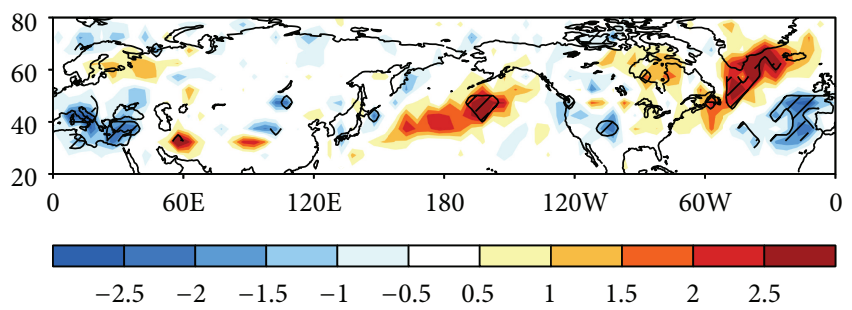

(b)

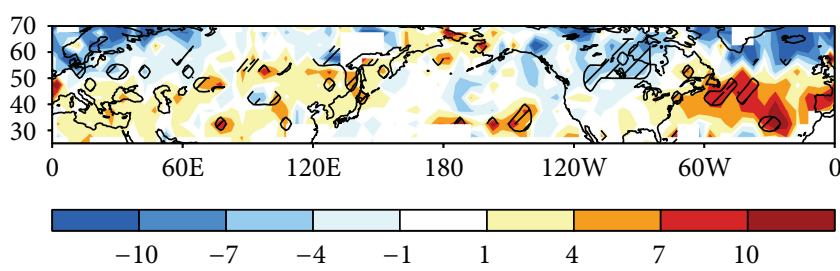

(c)

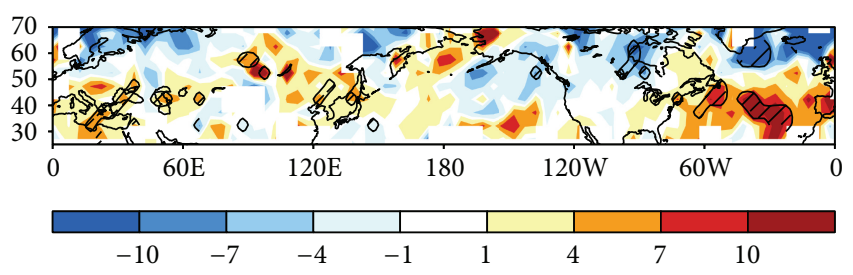

(d)

FIGURE 2: NH winter (JFM) NAO positive-NAO negative cyclone track frequency composite for (a) NCEP1_5801, (b) like (a) but for ERA40_5801. Units: no. of cyclones per $5^{\circ}$ Lat $\times 5^{\circ}$ Lon box. Hatched areas are significant at $90 \%$ for 2 -tailed $t$-test. (c) NH winter (JFM) NAO positive-NAO negative cyclone track intensity composite for NCEP1_5801. (d) like (c) but for ERA40_5801. Units: hPa. Hatched areas are significant at $90 \%$ for 2 -tailed $t$-test.

negative years is also noted from Japan northeastward to the western tip of the Aleutians in both datasets, with the area of significance confined to south of the Aleutians for ERA40_5801 (Figure 2(b)). Overall, the large spatial extent of statistical significance, coupled with the prevalence of several overlapping significant features in all of the reanalysis datasets, speaks to the hemispheric extent of the positive NAO impact on cyclone tracks. Since there is a risk of contamination from external forcing such as El Niño and the PNA, partial correlation will be useful in verifying the hemispheric extent to our NAO composite.

Similar to the NAO frequency composites, the NAO intensity composites extend beyond the centers of action in the North Atlantic (Figures 2(c) and 2(d)). For example, more intense cyclones are found generally along $70^{\circ} \mathrm{N}$ from $120^{\circ} \mathrm{W}$ to $70^{\circ} \mathrm{E}$ for positive $\mathrm{NAO}$ relative to negative NAO. Less intense cyclones for positive NAO relative to negative NAO are found across the North Atlantic along $40^{\circ} \mathrm{N}$ eastward to western Europe in both datasets (Figures 2(c) and 2(d)). As was the case for the frequency composite, a southward displacement of the polar jetstream is indicated for a negative NAO. Impacts of a negative NAO on cyclone tracks were investigated by Seager et al. [64], who found that precipitation anomalies in the western and southeastern US are due to a southward shift in the cyclone track. Nonsignificant decreases in intensity are located east of this zone across much of central Europe eastward to China (Figures 2(c) and 2(d)). Although there is good agreement among all of the datasets, regional differences are evident such as an area of more intense storms in positive $\mathrm{NAO}$ relative to negative $\mathrm{NAO}$ extending further west from Hudson Bay to Montana in NCEP1_5801 but not in ERA40_5801 (compare Figure 2(c) with Figure 2(d)). Assimilation/model differences are likely culprits for this difference.

PNA frequency and intensity composites are shown in Figure 3. Results from both datasets are consistent, with an increase (decrease) in cyclones in the central North Pacific, a decrease (increase) in cyclones in the Gulf of Alaska eastward across the northern US, and an increase (decrease) in cyclones along the US east coast during positive (negative PNA) (Figures 3(a) and 3(b)). Given the configuration of troughs and ridges associated with positive/negative phases of the PNA, this result is not surprising. However, we will see that when analyzing partial correlation, the east coast signal in cyclone track frequency will vanish when eliminating El Niño.

For the PNA intensity composite, more (less) intense cyclones are found in the North Pacific for both datasets associated with a stronger (weaker) Aleutian low during positive (negative) PNA (Figures 3(c) and 3(d)). An increase (decrease) in intensity for positive (negative) PNA is also evident across the northwestern US/southwestern Canada for NCEP1_5801 but not for ERA40_5801 (compare Figure 3(c) with Figure 3(d)). Data assimilation/model differences between the ERA-40 and NCEP reanalyses are likely causes in this data-sparse area. Further downstream, the effects of the PNA on cyclone intensity are more muted, with suggestions of a (nonsignificant) response of storm intensity to PNA from Iceland southward to the northeastern Atlantic occurring in NCEP1_5801 (Figure 3(c)). Overall, the PNA intensity composites suggest a robust signal across the North Pacific, with a decreased response further downstream, with differences between NCEP and ERA-40 reanalysis suggesting that some of the cyclone intensity response to PNA be a byproduct of assimilation differences.

Since the IOD's center of action is far removed from $\mathrm{NH}$ mid-latitude cyclone tracks, there was little impact of the IOD on $\mathrm{NH}$ cyclone track frequency and intensity in the correlation and intensity composites (not shown). However, frequency composite analysis did reveal an interesting pattern across Canada and the northern US (Figure 4). Figure 4 reveals a banded structure, with increased (decreased) cyclones over Central Canada northeastward to Hudson 


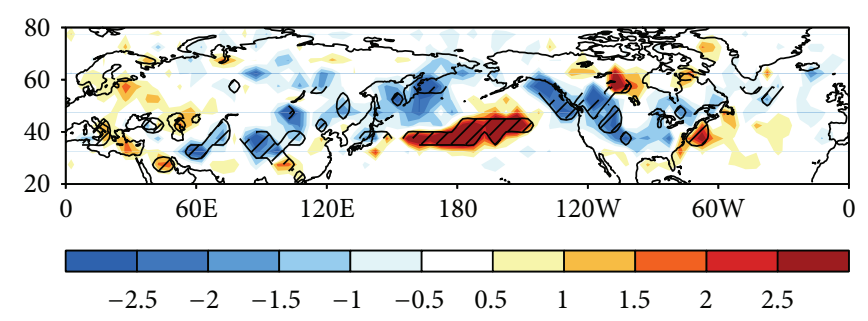

(a)

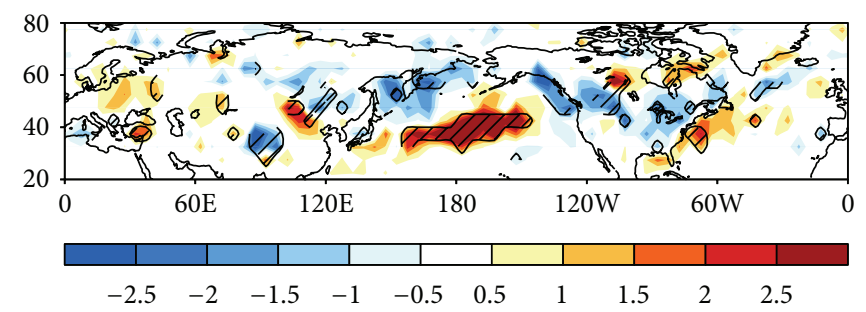

(b)

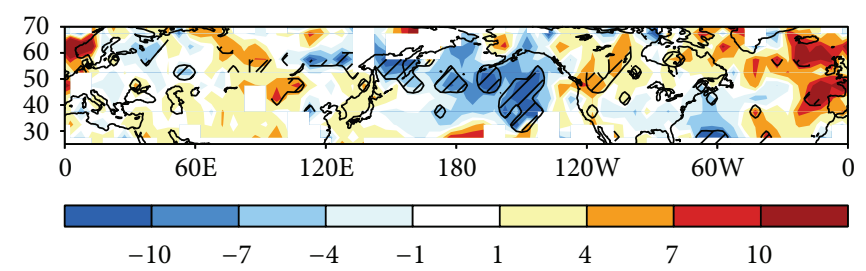

(c)

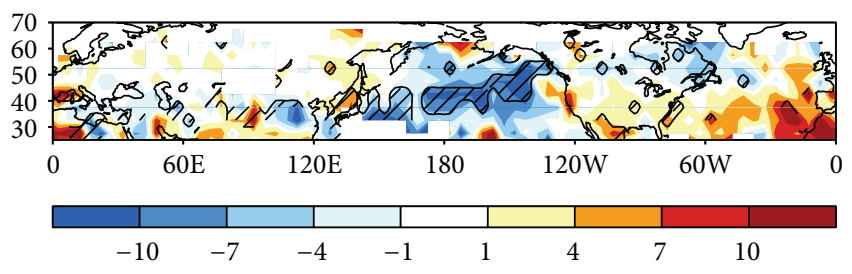

(d)

FIGURE 3: NH winter (JFM) PNA positive-PNA negative cyclone track frequency composite for (a) NCEP1_5801, (b) like (a) but for ERA40_5801. Units: no. of cyclones per $5^{\circ}$ Lat $\times 5^{\circ}$ Lon box. Hatched areas are significant at $90 \%$ for 2 -tailed $t$-test. (c) NH winter (JFM) $\mathrm{NAO}$ positive-NAO negative cyclone track intensity composite for NCEP1_5801. (d) like (c) but for ERA40_5801. Units: hPa. Hatched areas are significant at $90 \%$ for 2 -tailed $t$-test.

Bay, decreased (increased) cyclones from the central US to the southeastern tip of Hudson Bay, and increased (decreased) cyclones from the US mid-Atlantic coast to Nova Scotia during positive (negative) IOD. Interestingly, the negative band from the central US to southeastern Hudson Bay in NCEP1_5801 resembles a "lee cyclogenesis" cyclone track, while the negative area originates further north in ERA40_5801 and resembles an "Alberta Clipper" track (compare Figure 4(a) with Figure 4(b)).

Given that statistically significant areas are fairly limited in areal coverage for the banded structures seen in IOD composites, caution needs to be applied to interpreting the results. However, they are evident across all of the datasets despite their fairly localized regional extent. The banded structure

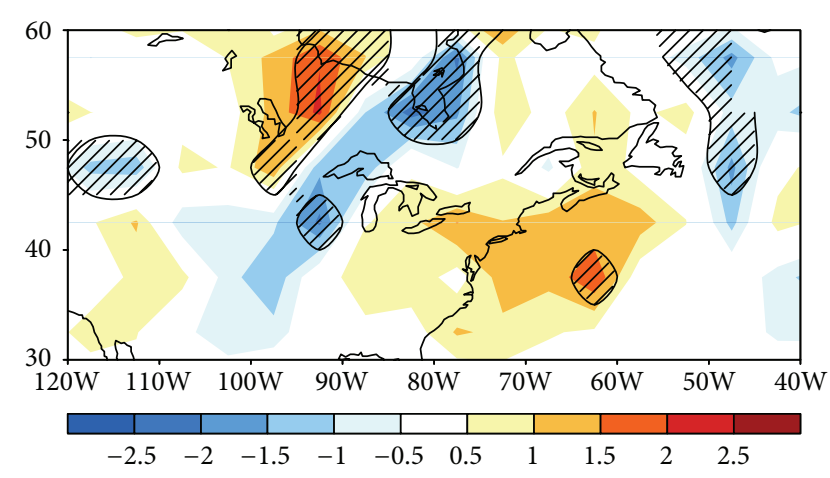

(a)

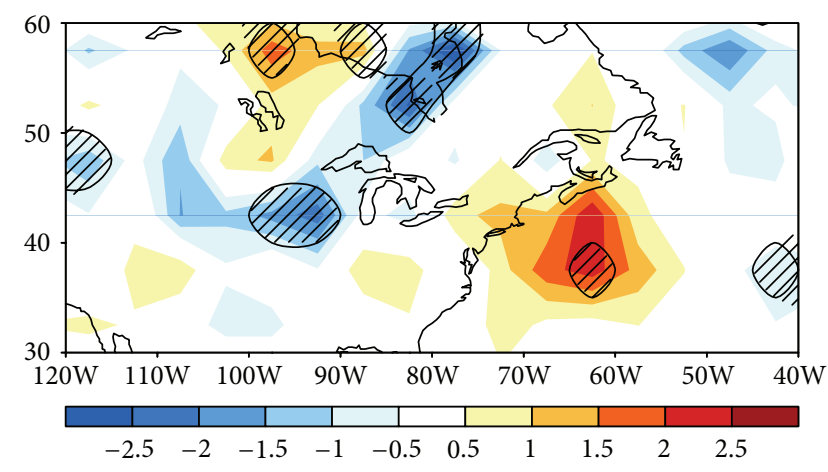

(b)

FIGURE 4: OND cyclone track frequency composite for (a) IOD positive relative to negative for NCEP1_5801 (shaded). 2-tailed 90\% significance (hatched), (b) like (a) but for ERA40_5801 Units: number of storms per winter for $a 5^{\circ} \times 5^{\circ}$ box.

is suggestive of a Rossby wave train response to IOD as suggested by Saji and Yamagata [48], Min et al. [52], and Small et al. [65]. More research using higher-resolution reanalysis datasets and model simulations is needed to further explore any potential IOD/NH cyclone relationships.

3.2. Partial Correlation Analysis. The correlation between cyclone track frequency and El Niño (eliminating PNA and NAO) is shown in Figure 5. For all datasets, a band of positive correlations containing large areas of significance extend from the Gulf of Mexico northeastward along the southeastern US coast, although it is much weaker in NCEP1_7910 (Figure 5(c)). When comparing NCEP1_5801 with ERA40_5801, the responses are quite similar, although there is a significant negative correlation south of Greenland in ERA40_5801 (compare Figure 5(a) with Figure 5(b)). Differences between NCEP1_7910 and NCEP1_5078 include negative correlations across the U.S/Canadian border in NCEP1_5078, which is shifted poleward across central Canada in NCEP1_7910 (compare Figure 5(c) with Figure 5(d)). This may be related to low-level warming at high-latitudes during the 1980's and 1990's as suggested by Greatbatch et al. [66], which would result in a poleward shift of the mid-latitude baroclinic zone. Major differences were also found in all datasets with respect to the El Niño frequency composite analysis including (1) the absence of 


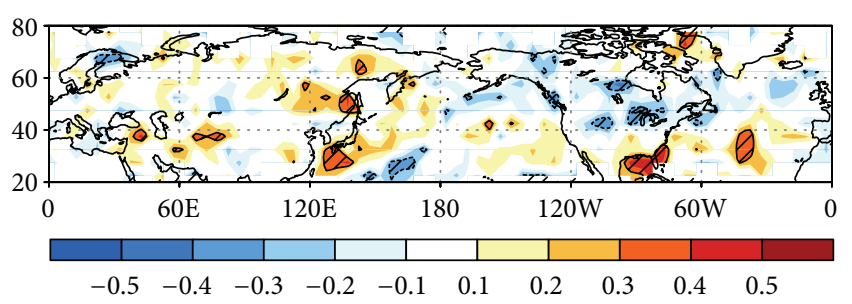

(a)

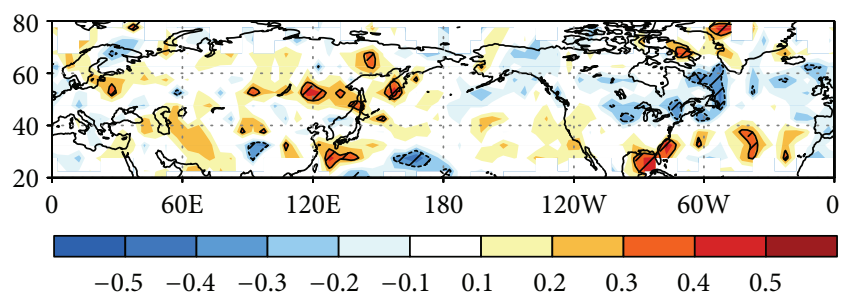

(b)

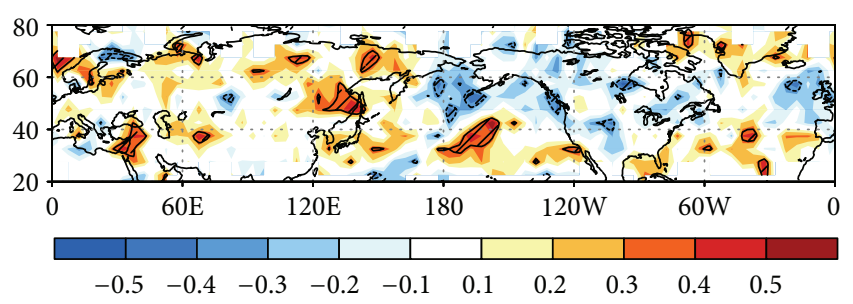

(c)

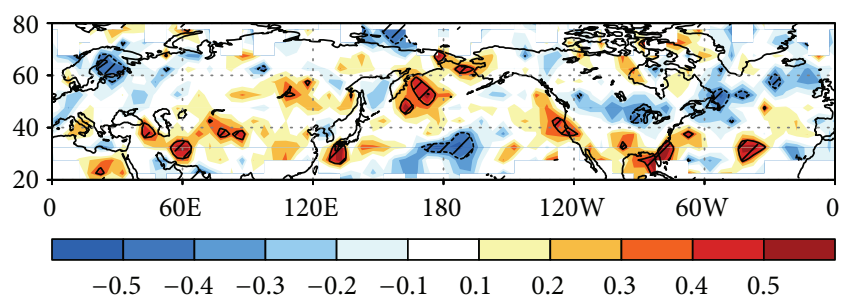

(d)

FIGURE 5: Partial correlation coefficient for JFM cyclone frequency versus ENSO (excluding PNA and NAO). Correlation (shaded). 2-tailed 90\% significance (hatched) for (a) NCEP1_5801, (b) ERA40_5801, (c) NCEP1_7910, and (d) NCEP1_5078.

positive correlations in the North Pacific where the composite analysis suggests a well-defined cyclone track during El Niño and (2) a less distinct zone of negative correlation across the northern US/southern Canada, where the composites suggest a more active cyclone track during La Niña stretching from the Gulf of Alaska eastward into the North Atlantic (compare Figure 5 with Figure 1 for both points). As will be shown subsequently, the elimination of the PNA from the El Niño correlation plays a role in the differences between the composite analysis and the partial correlation analysis.

For the PNA correlation, significant positive correlations are found in the North Pacific south of the Aleutians, with negative correlations northeast of Japan for all datasets (Figure 6). ERA40_5801 and NCEP1_5801 produced similar responses, although significant negative correlations extended as far west as Iran in NCEP1_5801 (compare Figure 6(a) with Figure 6(b)). Larger differences are noted

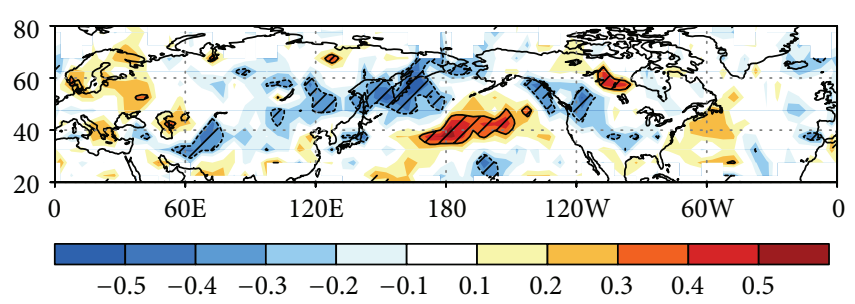

(a)

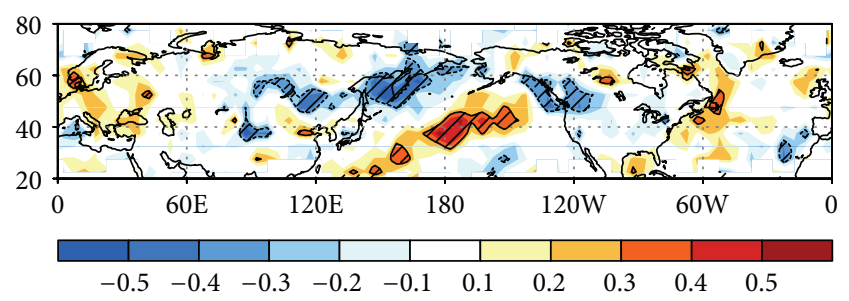

(b)

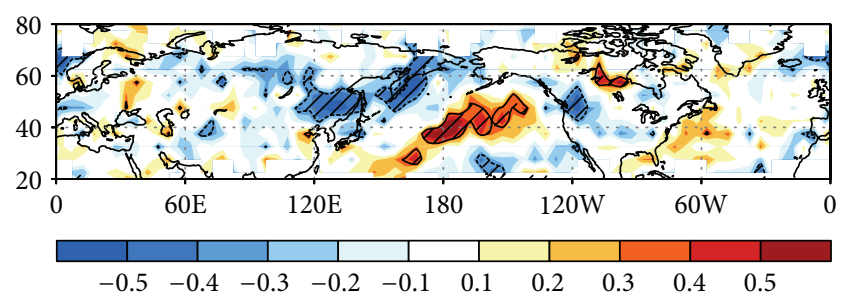

(c)

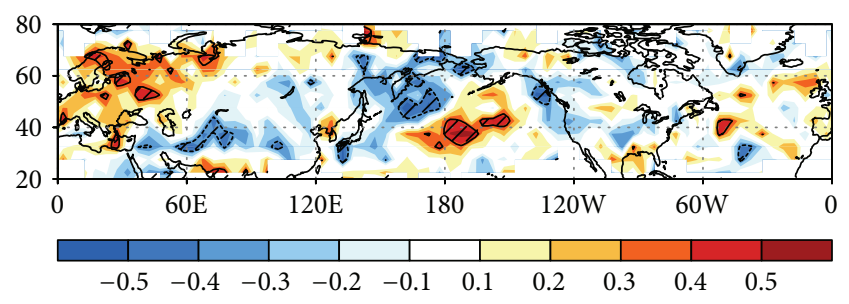

(d)

FIGURE 6: Partial correlation coefficient for JFM cyclone frequency versus PNA (excluding ENSO and NAO). Correlation (shaded). 2-tailed 90\% significance (hatched) for (a) NCEP1_5801, (b) ERA40_5801, (c) NCEP1_7910, and (d) NCEP1_5078.

when comparing NCEP1_7910 with NCEP1_5078 (Figures 6(c) and 6(d)). For example, NCEP1_5078 shows a large area of positive correlation across central and northern Europe, which is completely absent in NCEP1_7910 (compare Figure 6(c) with Figure 6(d)). The positive correlations across Europe in NCEP1_5078 are consistent with the negative phase of the NAO, suggesting a negative correlation between the NAO and PNA during this period. This is consistent with Pinto et al. [57], who found a significant negative correlation between the NAO and PNA in three simulations of the ECHAM model. Pinto et al. [57] found this relationship lacking when assessing ERA-40 and NCEP reanalysis data from 1973 to 1994, which was attributed to an inactive period in the coupling strength between NAO and PNA. The lack of this feature in 1979-2010 suggests that the coupling strength between the PNA and NAO was weak from 1979 to 2010 and strong from 1950 to 1978 . When comparing the PNA 


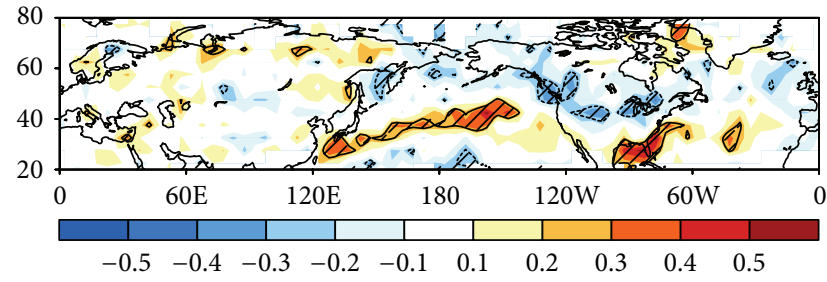

(a)

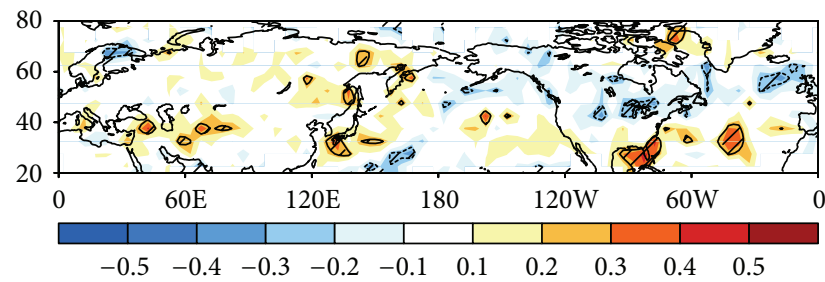

(b)

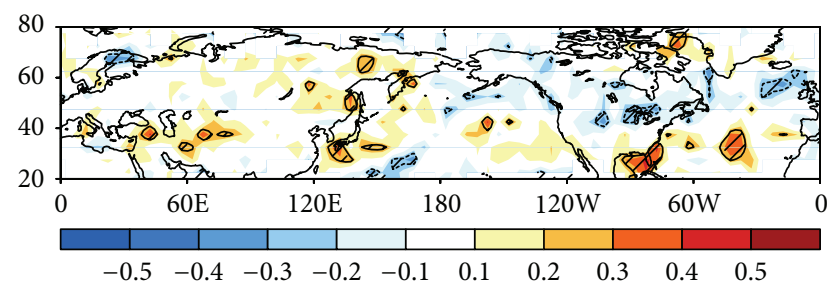

(c)

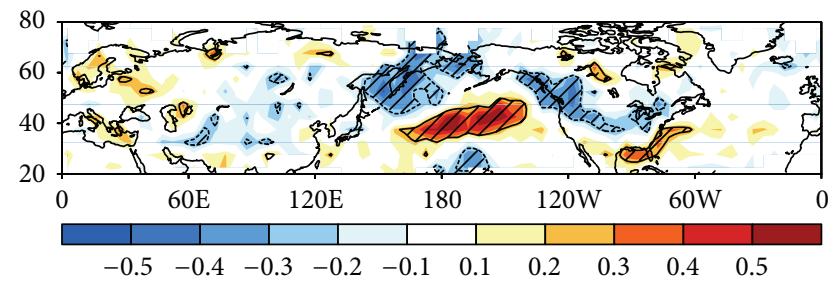

(d)

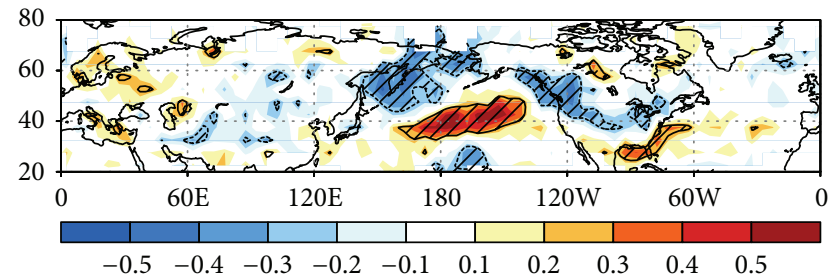

(e)

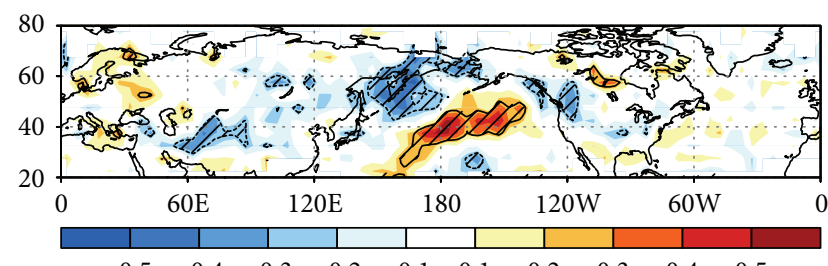

(f)

Figure 7: (a)-(c) Correlation coefficient for JFM cyclone frequency versus ENSO for (a) total correlation, (b) excluding PNA, (c) excluding PNA and NAO. (d)-(f) Correlation coefficient for JFM cyclone frequency versus PNA for (d) total correlation, (e) excluding NAO, and (f) excluding NAO and ENSO. Correlation (shaded) 2-tailed 95\% significance (hatched).

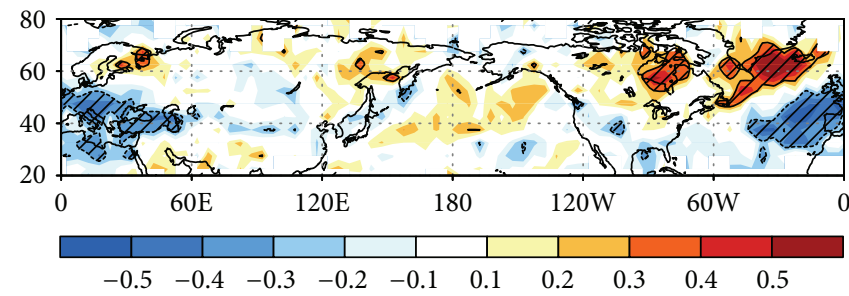

(a)

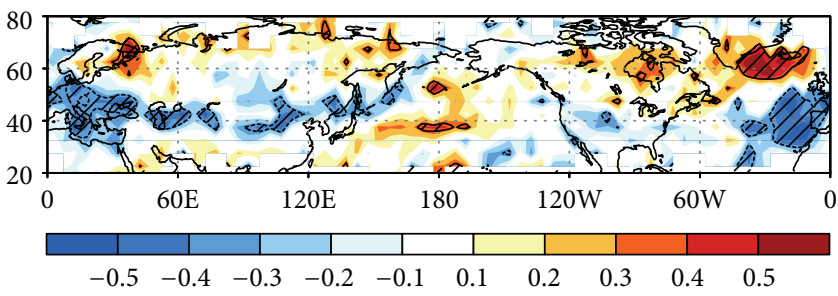

(c)

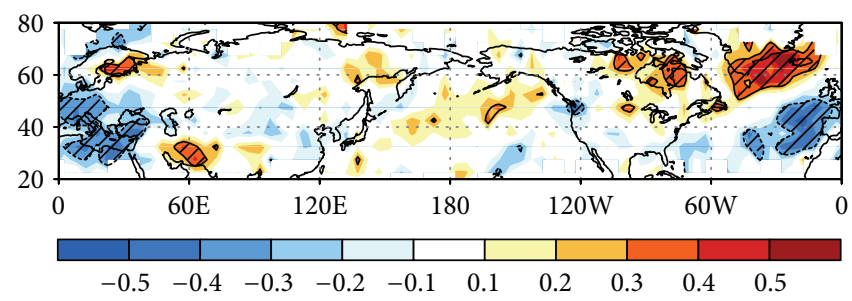

(b)

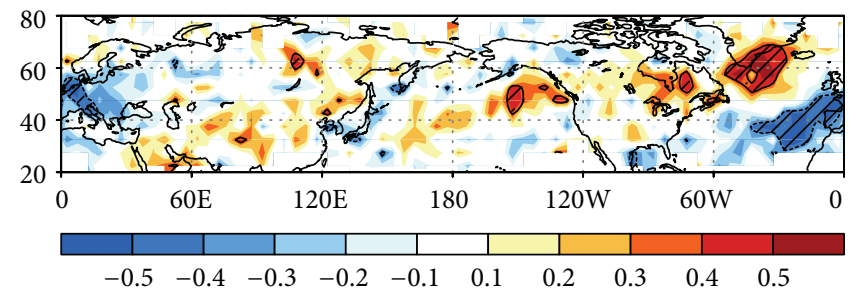

(d)

FIGURE 8: Correlation coefficient for JFM cyclone frequency versus NAO (excluding PNA and ENSO). Correlation (shaded) 2-tailed 95\% significance (hatched) for (a) NCEP1_5801, (b) ERA40_5801, (c) NCEP1_7910, and (d) NCEP1_5078.

correlation to the PNA composite, a major difference is seen along the US east coast, where the composite analysis shows an increase (decrease) in cyclones for positive (negative) PNA. However, the correlation analysis lacks this feature (compare Figure 6 with Figure 3).
As discussed above, the El Niño and PNA correlations showed major differences with their composites in specific regions. To investigate further, we recomputed the El Niño correlation for NCEP1_5010 with (1) no factors eliminated, that is, a full correlation, (2) a partial correlation with 

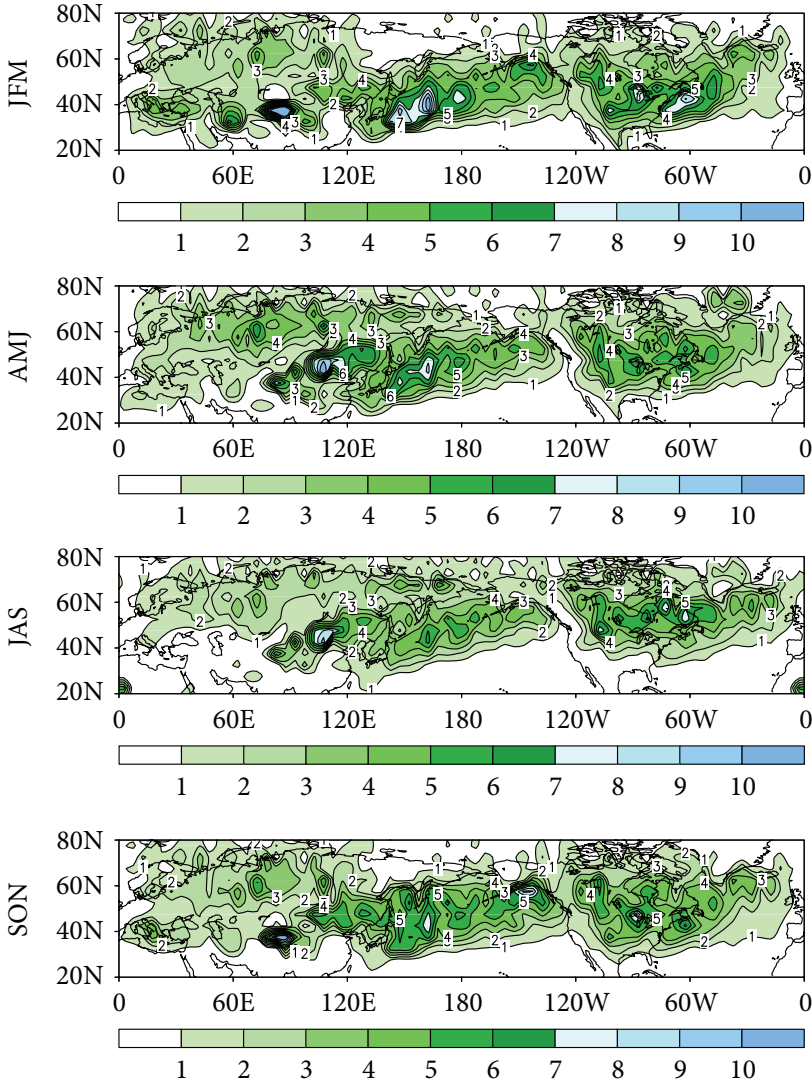

(a)
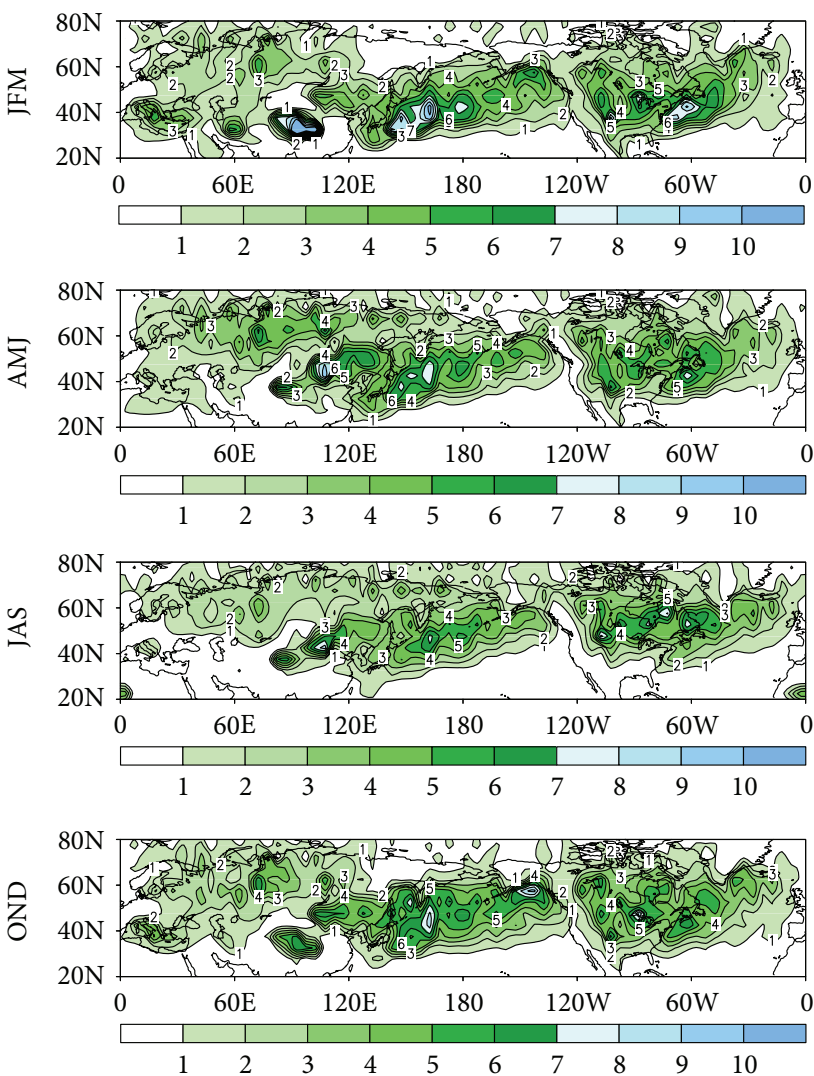

(c)
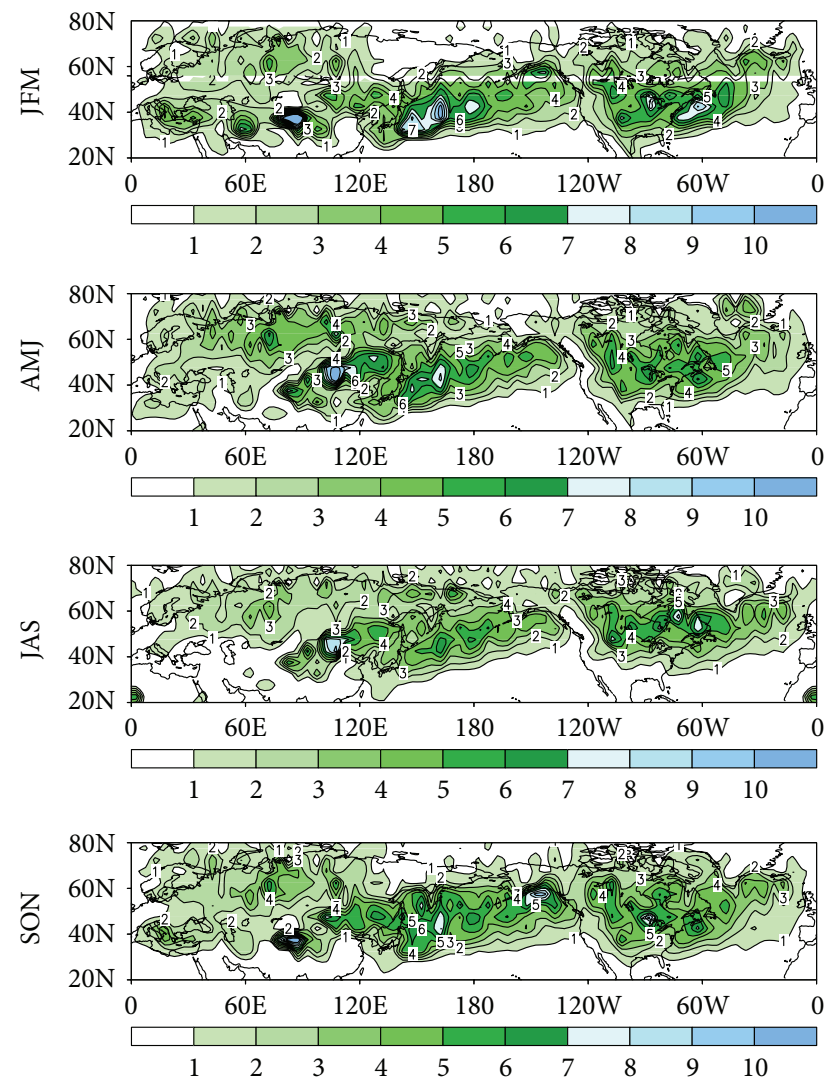

(b)
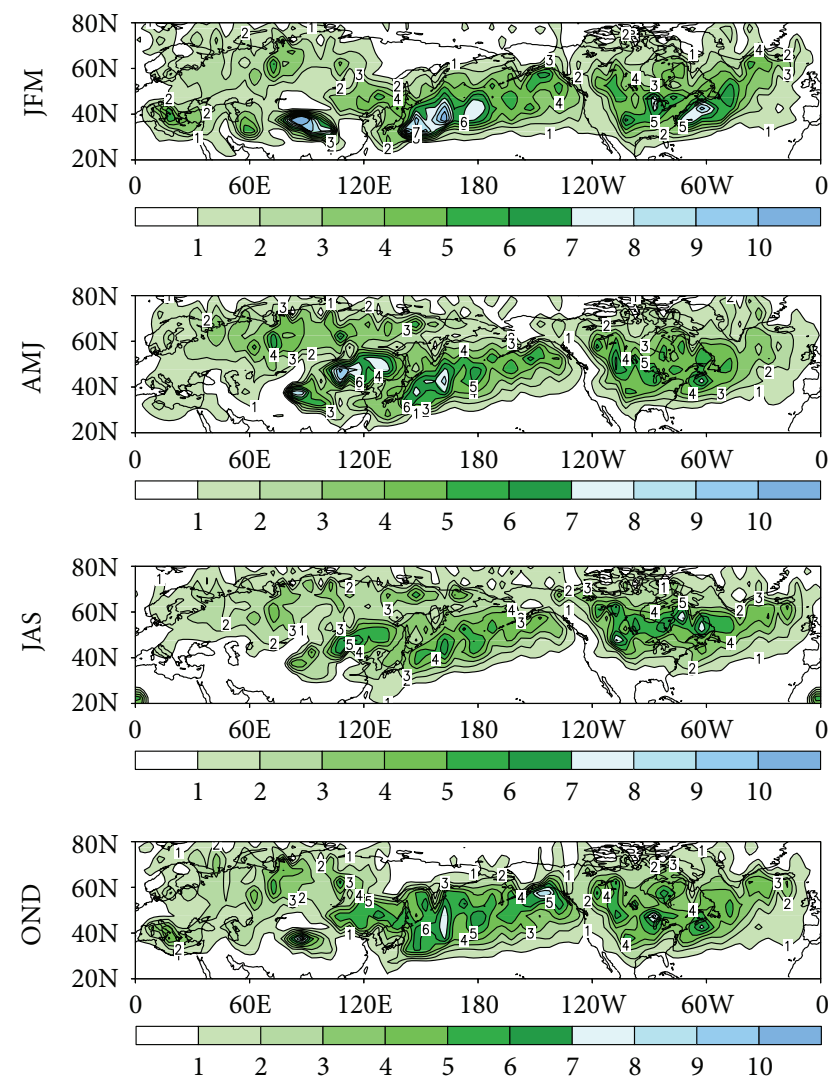

(d)

FIgURE 9: Continued. 

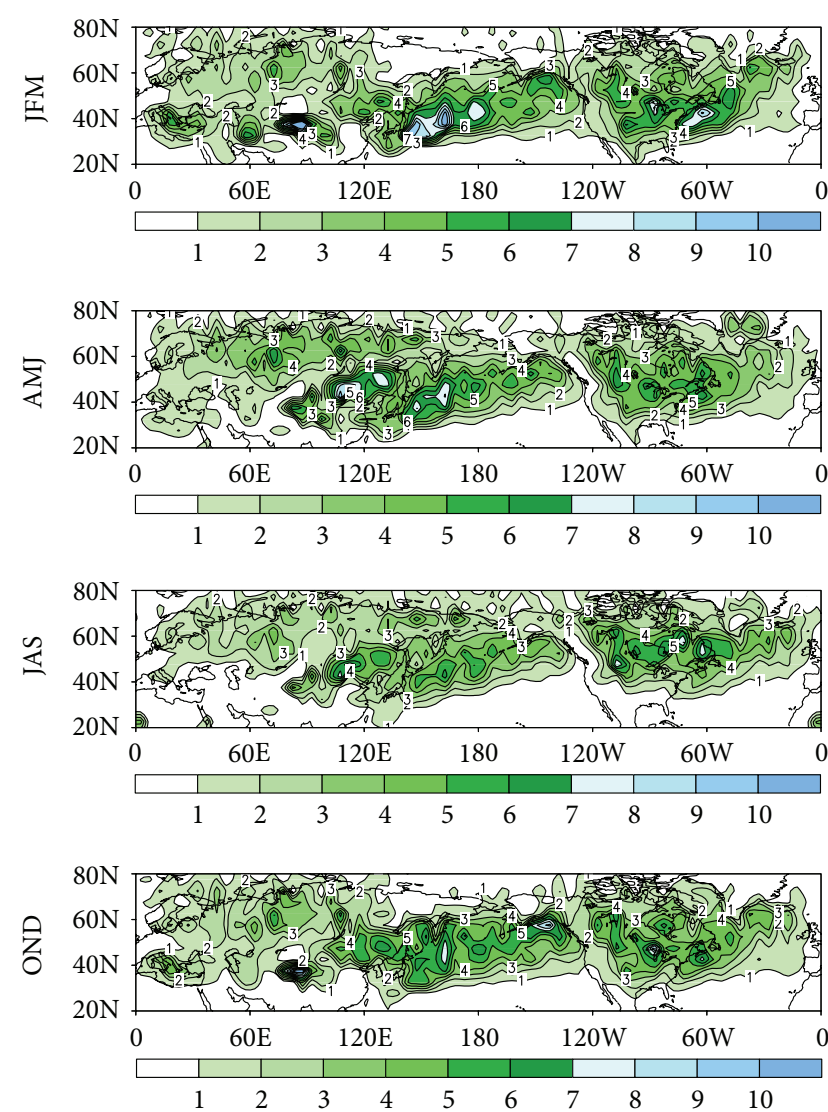

(e)
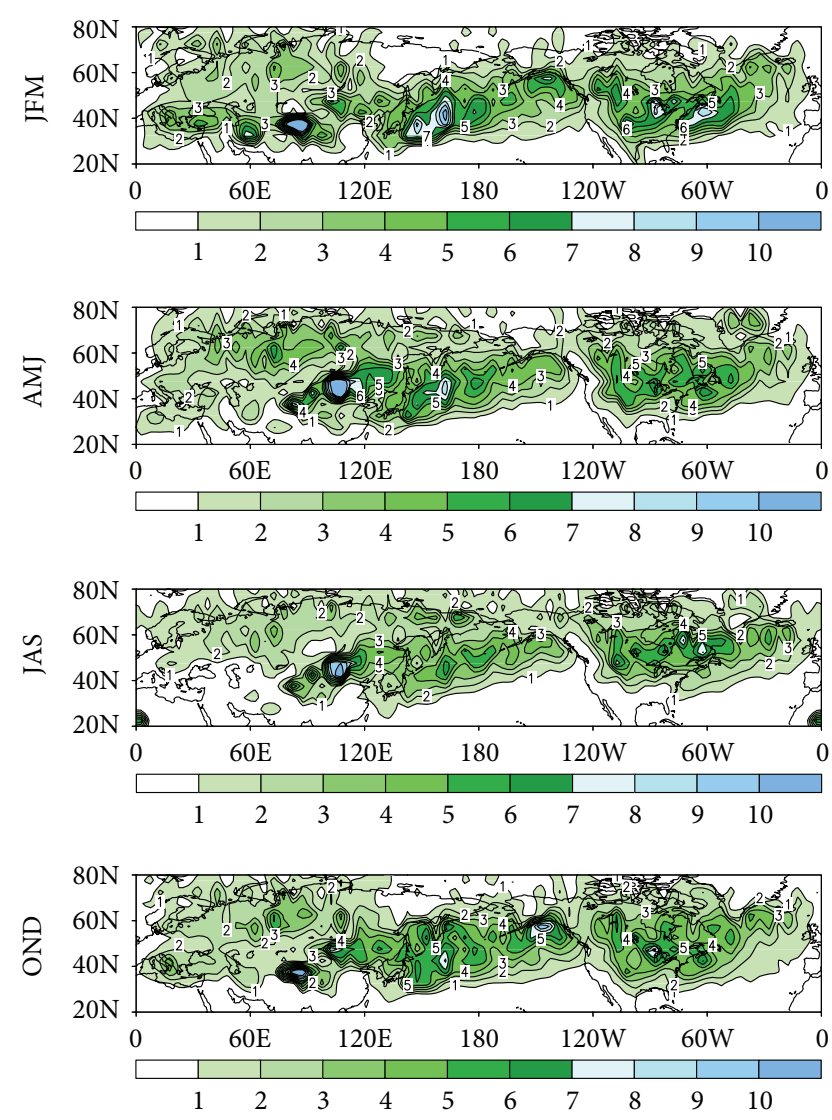

(f)

FIGURE 9: Cyclone track frequency climatology (shaded) for (a) NCEP1_5010 (JFM, AMJ, JAS, OND), (b) like (a) but for NCEP1_5801, and (c) like (a) but for ERA40_5801. Units: number of storms per winter for a $5^{\circ} \times 5^{\circ}$ box. Cyclone track frequency climatology (shaded) for (d) like (a) but for Re27910, (e) like (a) but for NCEP1_7910, and (f) like (a) but for NCEP1_5078. Units: number of storms per winter for a $5^{\circ} \times 5^{\circ}$ box.

the PNA removed, and (3) a partial correlation with the PNA and NAO removed (Figures $7(a)-7(c)$ ). When assessing the full correlation (Figure 7(a)), the results resemble the composite analysis (compare with Figure 1), with positive correlations in the central North Pacific and along the US east coast and negative correlations from the Gulf of Alaska eastward across the northern US. When the PNA is removed (Figure 7(b)), the North Pacific and northern US correlations are eliminated, leaving only the US east coast correlation. Eliminating the NAO (Figure 7(c)) does little to the correlation pattern, which indicates that the NAO does not play a major role in the El Niño correlation. Since El Niño affects the PNA, the full correlation shows both of these effects. However, the elimination of the PNA suggests that the North Pacific/northern US correlations are only indirectly caused by El Niño via the PNA, while the US east coast correlation is a direct result of anomalous heating in the Equatorial Pacific due to El Niño.

In a similar fashion, we also recomputed the PNA correlation as a (1) full correlation with no factors eliminated (2) partial correlation removing effects of the NAO, and (3) partial correlation eliminating El Niño and the NAO (Figures $7(\mathrm{~d})-7(\mathrm{f})$ ). The full correlation (Figure $7(\mathrm{~d})$ ) is similar to the composite analysis, with positive correlations in the central
North Pacific and along the US east coast and negative correlations northeast of Japan and across the northern US (compare Figure 7(d) with Figure 3). When eliminating the $\mathrm{NAO}$, little difference is seen, demonstrating that the NAO does not play a significant role in cyclone tracks when assessing the PNA (Figure 7(e)). However, this result may also be the result of a lack of coupling between the PNA and cyclone frequency tracks for this period in the reanalysis data as suggested by Pinto et al. [57]. When El Niño and the NAO are eliminated (Figure $7(\mathrm{f})$ ), much of the signal across the northern US and along the US east coast vanishes. These results are consistent with the El Niño analysis in Figures $7(\mathrm{a})-7(\mathrm{c})$ and suggest that, by itself, the PNA has a significant effect on cyclone tracks in the North Pacific. However, El Niño needs to be operative to produce effects further downstream across the northern US/US east coast.

Unlike the PNA and El Niño correlations, the NAO partial correlation is more robust when compared with the NAO composite analysis (Figure 8). For example, significant positive correlations are found south of Greenland, while significant negative correlations occur in the central North Atlantic, consistent with the NAO composite analysis for all datasets (compare Figure 8 with Figure 2). Positive correlations (with areas of significance) are also found in the central 

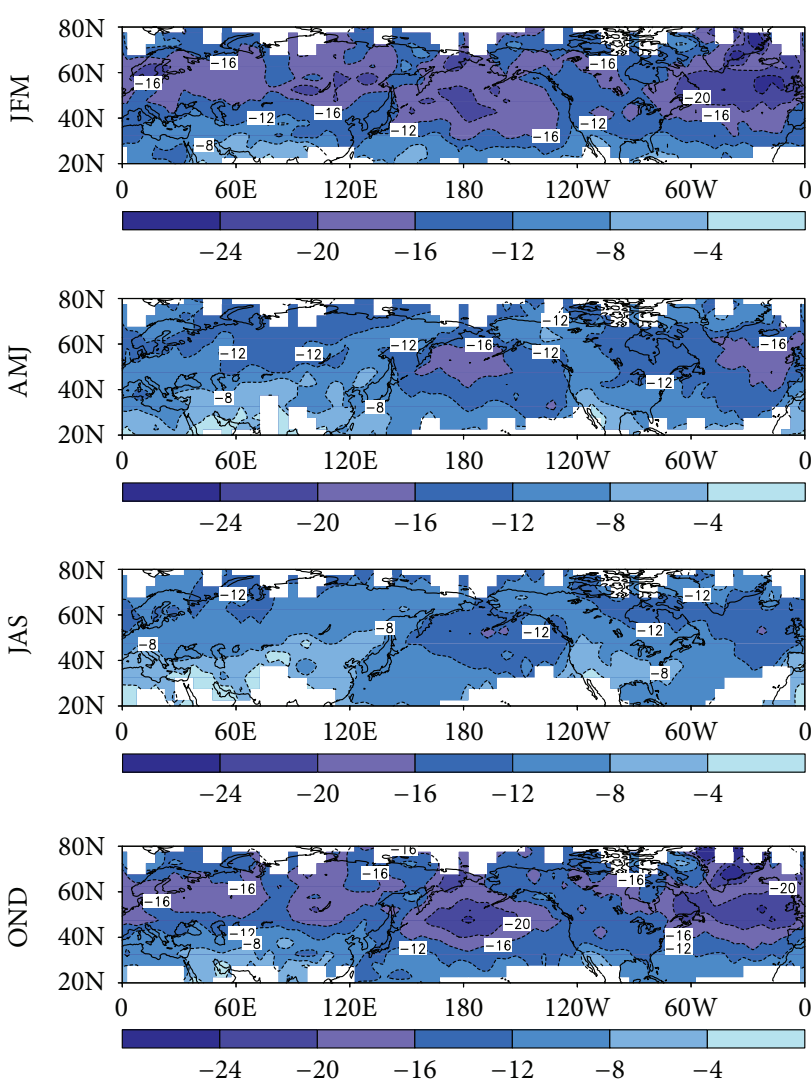

(a)
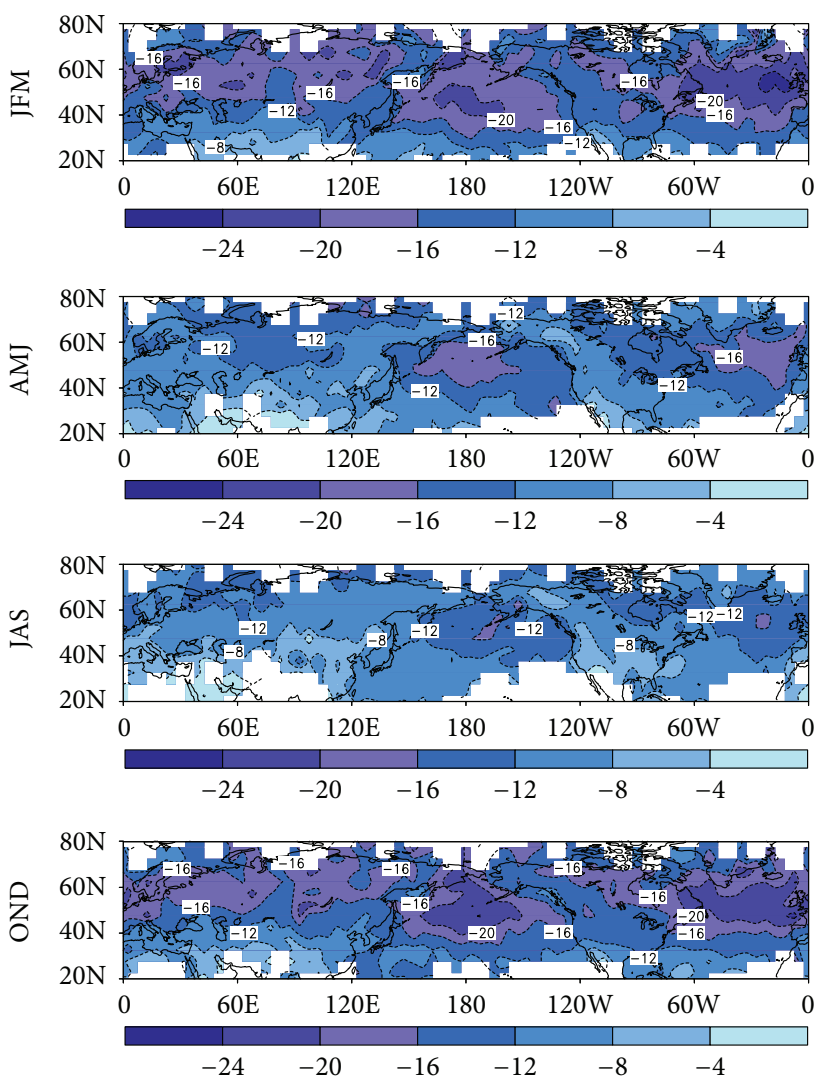

(c)
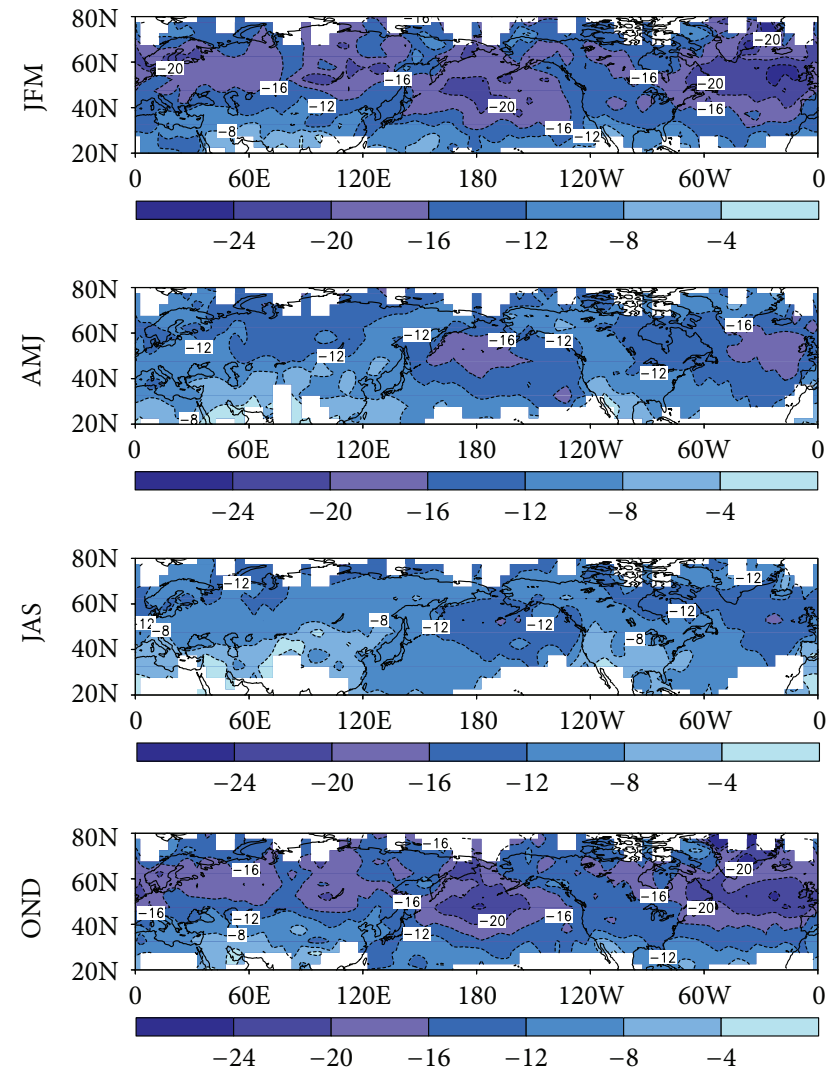

(b)
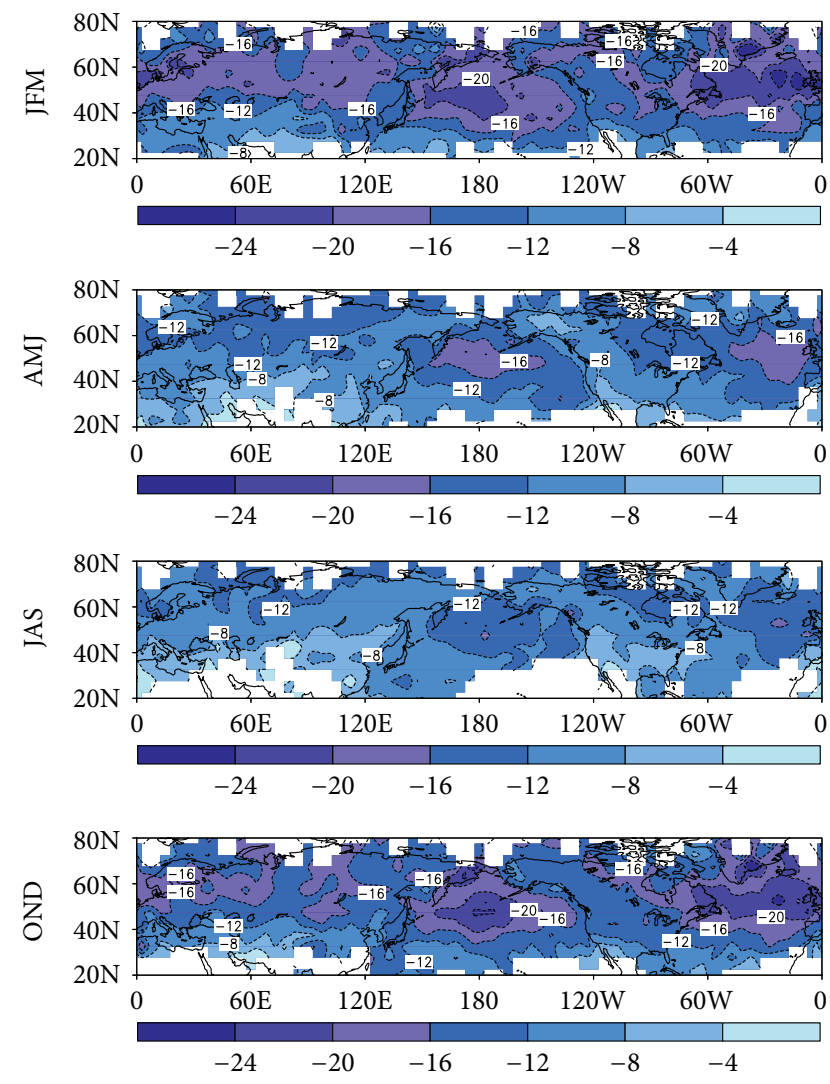

(d)

Figure 10: Continued. 

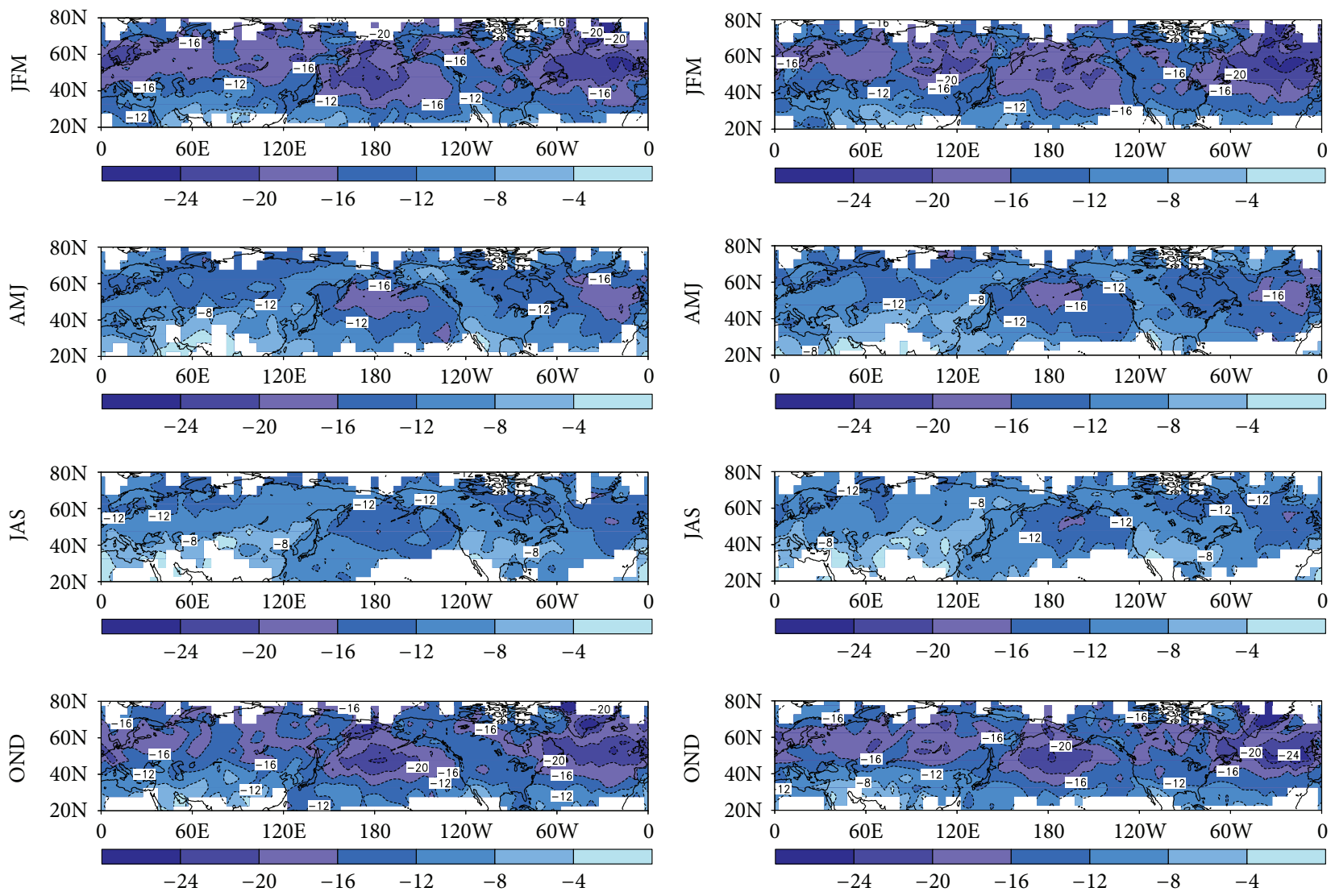

(e)

(f)

FIGURE 10: Cyclone track intensity climatology (shaded). Intensity derived by subtracting regressed climatological mean from cyclone track mean (units: hPa) for (a) NCEP1_5010 (JFM, AMJ, JAS, OND), (b) like (a) but for NCEP1_5801, and (c) like (a) but for ERA40_5801. Cyclone track intensity climatology (shaded). Intensity derived by subtracting regressed climatological mean from cyclone track mean (units: hPa) for (d) like (a) but for Re27910, (e) like (a) but for NCEP1_7910, and (f) like (a) but for NCEP1_5078.

North Pacific (Figure 8), which is far removed from the NAO teleconnection areas. However, some differences are seen between NCEP1_7910 and NCEP1_5078, with NCEP1_7910 showing a zone of negative correlation across Asia relative to NCEP1_5078 (compare Figure 8(c) with Figure 8(d)). An area of positive correlation in the North Pacific is also displaced eastward to the Gulf of Alaska in Re5078 relative to NCEP1_7910 (compare Figure 8(c) with Figure 8(d)). A possible reason for these differences is an altered response of cyclone track frequency to the NAO in different time periods similar to the southeastward shift of the cyclone track in 19581978 relative to $1979-1999$ found by Gulev et al. [39].

\section{Conclusions}

Composite analyses showed surprisingly good agreement especially for El Niño, NAO, and the PNA. Interestingly, NAO impacts were also noted as far west as the North Pacific, which was confirmed by partial correlation analysis. The results for the IOD showed some interesting features across the northern US/Canada possibly related to Rossby wave propagation. However, this must be viewed as tenuous given the lack of verification from correlation analysis. Our composite analysis also showed that caution is advised when assessing interannual variability for regional spatial scales, since regions of significance vary either as a result of the time period chosen for the composite analysis or from differences in model/data assimilation techniques between the reanalysis datasets themselves. This was especially true when comparing intensity composites, such as the PNA intensity composite differences between ERA-40 and NCEP reanalysis datasets.

Partial correlation was useful in verifying which components of the composite analysis were most robust. The PNA exhibited a positive correlation with cyclone frequency across Europe in the 1950-1978 period compared with 19792010, suggesting that the coupling strength between the NAO and PNA was greater in the former period than the latter period. For the NAO, the correlations were most similar to the composite analysis suggesting that El Niño and the PNA do not play a significant role in the NAO's impact on cyclone tracks. However, the El Niño correlation was not consistent with the El Niño composite in the North Pacific nor was the PNA correlation consistent with the PNA composite across the northern US/US east coast. Our results suggest that El Niño directly impacts the US east coast cyclone track, while the North Pacific and northern US cyclone tracks are first 
modulated by the PNA. Likewise, the PNA directly affects North Pacific cyclone tracks, while downstream effects across the northern US and the US east coast are modulated by El Niño. For the NAO, differences between NCEP1_7910 and NCEP1_5078 were noted across Asia, the Gulf of Alaska, and the Mediterranean, suggesting that a different response of storm tracks the NAO between these two time periods.

While we are encouraged by the many similarities we see related to the interannual variability of storm tracks in the coarse-gridded datasets, we also find that caution is advised, since interannual variability is sensitive to choice of reanalysis datasets, choice of time period analyzed, and impacts from other external climate forcings. In addition, results may differ if other methodologies are chosen as suggested by Neu et al. [33]. Future work will focus on analyzing cyclone tracks in the higher-resolution CFS reanalysis and NASA MERRA datasets.

\section{Appendices}

\section{A. Cyclone Seasonal Frequency Climatologies for Various Reanalysis Products}

See Figure 9.

\section{B. Cyclone Seasonal Intensity Climatologies for Various Reanalysis Products}

See Figure 10.

\section{Conflict of Interests}

Dr. Timothy Eichler and Mr. Jon Gottschalck declare that there is no conflict of interests regarding the publication of this paper.

\section{References}

[1] M. L. Blackmon, "A climatological spectral study of the $500 \mathrm{mb}$ geopotential height of the Northern Hemisphere," Journal of the Atmospheric Sciences, vol. 33, no. 8, pp. 1607-1623, 1976.

[2] M. L. Blackmon, J. M. Wallace, N. C. Lau, and S. L. Mullen, "An observational study of the Northern Hemisphere wintertime circulation," Journal of the Atmospheric Sciences, vol. 34, no. 7, pp. 1040-1053, 1977.

[3] J. M. Wallace, G.-H. L. Gyu-Ho Lim, and M. L. Blackmon, "Relationship between cyclone tracks, anticyclone tracks and baroclinic waveguides," Journal of the Atmospheric Sciences, vol. 45, no. 3, pp. 439-462, 1988.

[4] B. J. Hoskins and P. J. Valdes, "On the existence of storm-tracks," Journal of the Atmospheric Sciences, vol. 47, no. 15, pp. 1854-1864, 1990.

[5] E. K. M. Chang and Y. Fu, "Using mean flow change as a proxy to infer interdecadal storm track variability," Journal of Climate, vol. 16, no. 13, pp. 2178-2196, 2003.

[6] E. K. M. Chang, "Are the Northern Hemisphere winter storm tracks significantly correlated?" Journal of Climate, vol. 17, no. 21, pp. 4230-4244, 2004.
[7] V. B. Rao, A. M. C. do Carmo, and S. H. Franchito, "Seasonal variations in the Southern Hemisphere storm tracks and associated wave propagation," Journal of the Atmospheric Sciences, vol. 59, no. 6, pp. 1029-1040, 2002.

[8] C. S. Frederiksen and J. S. Frederiksen, "A theoretical model of Australian northwest cloudband disturbances and Southern Hemisphere storm tracks: the role of SST anomalies," Journal of the Atmospheric Sciences, vol. 53, no. 10, pp. 1410-1432, 1996.

[9] H. Nakamura and A. Shimpo, "Seasonal variations in the Southern Hemisphere cyclone tracks and jet stream as revealed in a reanalysis dataset," Journal of Climate, vol. 17,, pp. 1828$1844,2004$.

[10] S. Petterson, "Some aspects of the general circulation of the atmosphere," in Centenary Proceedings of the Royal Meteorological Society, pp. 120-155, Royal Meteorological Society, London, UK, 1950.

[11] W. H. Klein, "Principal tracks and mean frequencies of cyclones and anticyclones in the Northern Hemisphere," Research Paper \#40, U.S. Weather Bureau, Washington, DC, USA, 1957.

[12] J. Mather, H. Adams III, and G. Yoshioka, "Coastal storms of the Eastern United States," Journal of Applied Meteorology, vol. 3, pp. 693-706, 1964.

[13] C. Reitan, "Frequencies of cyclones and cyclogenesis for North America, 1951-1970," Monthly Weather Review, vol. 102, pp. 861868, 1974.

[14] K. M. Zishka and P. J. Smith, "The climatology of cyclones and anticyclones over North America and surrounding ocean environs for January and July 1950-1977," Monthly Weather Review, vol. 108, no. 4, pp. 387-401, 1980.

[15] F. Sanders and J. R. Gyakum, "Synoptic-dynamic climatology of the "Bomb" (extratropical surface cyclone)," Monthly Weather Review, vol. 108, no. 10, pp. 1589-1606, 1980.

[16] L. M. Whittaker and L. H. Horn, "Geographical and seasonal distribution of North American cyclogenesis, 1958-1977," Monthly Weather Review, vol. 109, no. 11, pp. 2312-2322, 1981.

[17] S. J. Lambert, "A cyclone climatology of the Canadian climate centre general circulation model," Journal of Climate, vol. 1, pp. 109-115, 1988.

[18] R. J. Murray and I. Simmonds, "A numerical scheme for tracking cyclone centres from digital data. Part I: development and operation of the scheme," Australian Meteorological Magazine, vol. 39, no. 3, pp. 155-166, 1991.

[19] S.-J. Chen, Y.-H. Kuo, P.-Z. Zhang, and Q.-F. Bai, "Synoptic climatology of cyclogenesis over east Asia, 1958-1987," Monthly Weather Review, vol. 119, no. 6, pp. 1407-1418, 1991.

[20] M. E. Hirsch, A. T. DeGaetano, and S. J. Colucci, "An East Coast winter storm climatology," Journal of Climate, vol. 14, no. 5, pp. 882-899, 2001.

[21] T. Eichler and W. Higgins, "Climatology and ENSO-related variability of North American extratropical cyclone activity," Journal of Climate, vol. 19, no. 10, pp. 2076-2093, 2006.

[22] D. Changnon, C. Merinsky, and M. Lawson, "Climatology of surface cyclone tracks associated with large central and Eastern U.S. Snowstorms, 1950-2000," Monthly Weather Review, vol. 136, no. 8, pp. 3193-3202, 2008.

[23] N. Tilinina, S. K. Gulev, I. Rudeva, and P. Koltermann, "Comparing cyclone life cycle characteristics and their interannual variability in different reanalyses," Journal of Climate, vol. 26, pp. 6419-6438, 2013.

[24] K. I. Hodges, "A general method for tracking analysis and its application to meteorological data," Monthly Weather Review, vol. 122, no. 11, pp. 2573-2586, 1994. 
[25] K. I. Hodges, "Feature tracking on the unit sphere," Monthly Weather Review, vol. 123, no. 12, pp. 3458-3465, 1995.

[26] K. I. Hodges, "Spherical nonparametric estimators applied to the UGAMP model integration for AMIP," Monthly Weather Review, vol. 124, no. 12, pp. 2914-2932, 1996.

[27] K. I. Hodges, "Adaptive constraints for feature tracking," Monthly Weather Review, vol. 127, no. 6, pp. 1362-1373, 1999.

[28] B. J. Hoskins, J. Boyle, and C. Thorncroft, "A comparison of recent reanalysis datasets using objective feature tracking: cyclone tracks and tropical easterly waves," Monthly Weather Review, vol. 131, pp. 2012-2037, 2003.

[29] M. D. S. Mesquita, D. E. Atkinson, and K. I. Hodges, "Characteristics and variability of storm tracks in the North Pacific, Bering Sea, and Alaska," Journal of Climate, vol. 23, no. 2, pp. 294-311, 2010.

[30] K. I. Hodges, R. W. Lee, and L. Bengtsson, "A comparison of extratropical cyclones in recent reanalyses ERA-Interim, NASA MERRA, NCEP CFSR, and JRA-25," Journal of Climate, vol. 24, no. 18 , pp. 4888-4906, 2011.

[31] M. G. Akperov and I. I. Mokhov, "A comparative analysis of the method of extratropical cyclone identification," Izvestiya, Atmospheric and Ocean Physics, vol. 46, no. 5, pp. 574-590, 2010.

[32] M. C. Serreze, "Climatological aspects of cyclone development and decay in the arctic," Atmosphere-Ocean, vol. 33, no. 1, pp. 1-23, 1995.

[33] U. Neu, M. G. Akperov, N. Bellenbaum et al., "IMILASTa community effort to intercompare extratropical cyclone detection and tracking algorithms: assessing method-related uncertainties," Bulletin of the American Meteorological Society, vol. 94, pp. 529-547, 2013.

[34] M. D. S. Mesquita, N. Gunnar Kvamstø, A. Sorteberg, and D. E. Atkinson, "Climatological properties of summertime extratropical storm tracks in the Northern Hemisphere," Tellus, Series A, vol. 60, no. 3, pp. 557-569, 2008.

[35] S. R. Leonard, J. Turner, and A. Van Der Wal, "An assessment of three automatic depression tracking schemes," Meteorological Applications, vol. 6, no. 2, pp. 173-183, 1999.

[36] J. M. Wallace and D. S. Gutzler, "Teleconnections in the geopotential height field during the Northern Hemisphere winter," Monthly Weather Review, vol. 109, no. 4, pp. 784-812, 1981.

[37] J. D. Horel and J. M. Wallace, "Planetary-scale atmospheric phenomena associated with the Southern Oscillation," Monthly Weather Review, vol. 109, no. 4, pp. 813-829, 1981.

[38] J. Noel and D. Changnon, "A pilot study examining U.S. winter cyclone frequency patterns associated with three ENSO parameters," Journal of Climate, vol. 11, no. 8, pp. 2152-2159, 1998.

[39] S. K. Gulev, O. Zolina, and S. Grigoriev, "Extratropical cycone variability in the Northern Hemisphere winter from the NCEP/NCAR reanalysis data," Climate Dynamics, vol. 17, no. 10, pp. 795-809, 2001.

[40] J. W. Hurrell, "Influence of variations in extratropical wintertime teleconnections on Northern Hemisphere temperature," Geophysical Research Letters, vol. 23, no. 6, pp. 665-668, 1996.

[41] J. W. Hurrell, Y. Kushnir, G. Ottersen, and M. Visbeck, "An overview of the North Atlantic oscillation," in The North Atlantic Oscillation: Climatic Significance and Environmental Impact, vol. 134 of Geophysical Monograph, pp. 1-35, American Geophysical Union, 2003.

[42] J. A. Bradbury, B. D. Keim, and C. P. Wake, "The influence of regional storm tracking and teleconnections on winter precipitation in the northeastern United States," Annals of the Association of American Geographers, vol. 93, no. 3, pp. 544-556, 2003.

[43] N. H. Saji, B. N. Goswami, P. N. Vinayachandran, and T. Yamagata, "A dipole mode in the tropical Indian ocean," Nature, vol. 401, no. 6751, pp. 360-363, 1999.

[44] K. Ashok, Z. Guan, and T. Yamagata, "Influence of the Indian Ocean Dipole on the Australian winter rainfall," Geophysical Research Letters, vol. 30, no. 15, pp. 1-6, 2003.

[45] L. Na, H. Honxia, M. Jinzhong, H. Feng, and B. Hongcum, "Spatial teleconnection field," Progress in Natural Science, vol. 15, pp. 1143-1147, 2005.

[46] K. Ashok, H. Nakamura, and T. Yamagata, "Impacts of ENSO and Indian Ocean dipole events on the Southern Hemisphere storm-track activity during austral winter," Journal of Climate, vol. 20, no. 13, pp. 3147-3163, 2007.

[47] N. Liu, H.-X. Chen, and L.-G. Lü, "Teleconnection of IOD signal in the upper troposphere over southern high latitudes," Journal of Oceanography, vol. 63, no. 1, pp. 155-157, 2007.

[48] N. H. Saji and T. Yamagata, "Possible impacts of Indian Ocean Dipole mode events on global climate," Climate Research, vol. 25, no. 2, pp. 151-169, 2003.

[49] T. Yamagata, J.-J. Luo, S. Masson, M. R. Jury, and S. A. Rao, “The coupled ocean-atmosphere variability in the tropical Indian Ocean," in Earth's Climate: The Ocean-Atmosphere Interaction, vol. 147 of Geophysical Monograph, pp. 189-211, American Geophysical Union, 2004.

[50] J. Yang, Q. Liu, Z. Liu, L. Wu, and F. Huang, "Basin mode of Indian Ocean sea surface temperature and Northern Hemisphere circumglobal teleconnection," Geophysical Research Letters, vol. 36, no. 19, Article ID L19705, 2009.

[51] H. Annamalai, H. Okajima, and M. Watanabe, "Possible impact of the Indian Ocean SST on the Northern Hemisphere circulation during El Niño," Journal of Climate, vol. 20, no. 13, pp. 3164-3189, 2007.

[52] J. Min, Q. Zhou, N. Liu, Q. Gao, and Z. Guan, “Teleconnection mode between IOD and Northern Hemisphere tropospheric circulation and its mechanism," Meteorology and Atmospheric Physics, vol. 100, no. 1-4, pp. 207-215, 2008.

[53] D. Dee, P. Berrisford, M. G. Bosilovich et al., "The use of reanalysis data for monitoring the state of the climate [in "State of the Climate in 2010"]," Bulletin of the American Meteorological Society, vol. 92, no. 6, pp. S34-S35, 2011.

[54] M. C. Serreze, F. Carse, R. G. Barry, and J. C. Rogers, "Icelandic low cyclone activity: climatological features, linkages with the $\mathrm{NAO}$, and relationships with recent changes in the Northern Hemisphere circulation," Journal of Climate, vol. 10, no. 3, pp. 453-464, 1997.

[55] E. Kalnay, M. Kanamitsu, R. Kistler et al., "The NCEP/NCAR 40-year reanalysis project," Bulletin of the American Meteorological Society, vol. 77, no. 3, pp. 437-471, 1996.

[56] S. M. Uppala, P. W. Kållberg, A. J. Simmons et al., “The ERA40 re-analysis," Quarterly Journal of the Royal Meteorological Society, vol. 131, no. 612, pp. 2961-3012, 2005.

[57] J. G. Pinto, M. Reyers, and U. Ulbrich, "The variable link between PNA and NAO in observations and in multi-century CGCM simulations," Climate Dynamics, vol. 36, no. 1, pp. 337354, 2011.

[58] V. E. Kousky and R. W. Higgins, "An alert classification system for monitoring and assessing the ENSO cycle," Weather and Forecasting, vol. 22, no. 2, pp. 353-371, 2007. 
[59] P. D. Jones, T. Jonsson, and D. Wheeler, "Extension to the North Atlantic Oscillation using early instrumental pressure observations from gibraltar and south-west Iceland," International Journal of Climatology, vol. 17, no. 13, pp. 1433-1450, 1997.

[60] X. Bai, J. Wang, C. Sellinger, A. Clites, and R. Assel, "Interannual variability of Great Lakes ice cover and its relationship to NAO and ENSO," Journal of Geophysical Research: Oceans, vol. 117, no. 3, Article ID C03002, 2012.

[61] J. C. Rogers, "The association between the North Atlantic Oscillation and the Southern Oscillation in the Northern Hemisphere," Monthly Weather Review, vol. 112, no. 10, pp. 19992015, 1984.

[62] D. Luo, Y. Diao, and S. B. Feldstein, "The variability of the Atlantic storm track and the North Atlantic Oscillation: a link between intraseasonal and interannual variability," Journal of the Atmospheric Sciences, vol. 68, no. 3, pp. 577-601, 2011.

[63] K. Walter and H. F. Graf, "The North Atlantic variability structure, storm tracks, and precipitation depending on the polar vortex strength," Atmospheric Chemistry and Physics, vol. 5, no. 1, pp. 239-248, 2005.

[64] R. Seager, Y. Kushnir, J. Nakamura, M. Ting, and N. Naik, "Northern Hemisphere winter snow anomalies: ENSO, NAO and the winter of 2009/10," Geophysical Research Letters, vol. 37, no. 14, Article ID L14703, 2010.

[65] D. Small, S. Islam, and M. Barlow, "The impact of a hemispheric circulation regime on fall precipitation over North America," Journal of Hydrometeorology, vol. 11, no. 5, pp. 1182-1189, 2010.

[66] R. J. Greatbatch, J. Lu, and K. A. Peterson, "Nonstationary impact of ENSO on Euro-Atlantic winter climate," Geophysical Research Letters, vol. 31, no. 2, pp. L02208-4, 2004. 

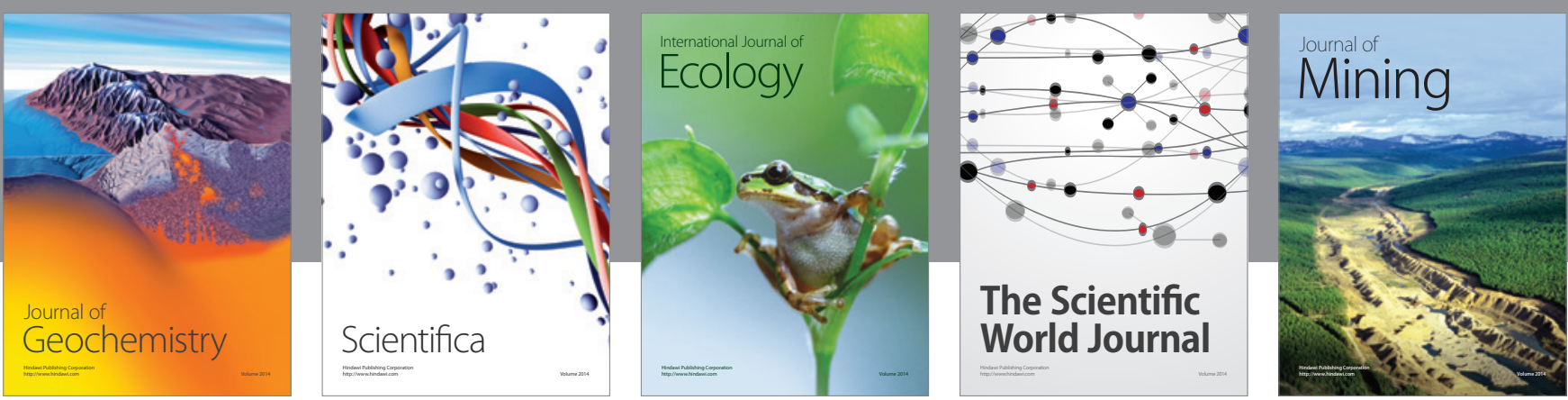

The Scientific World Journal
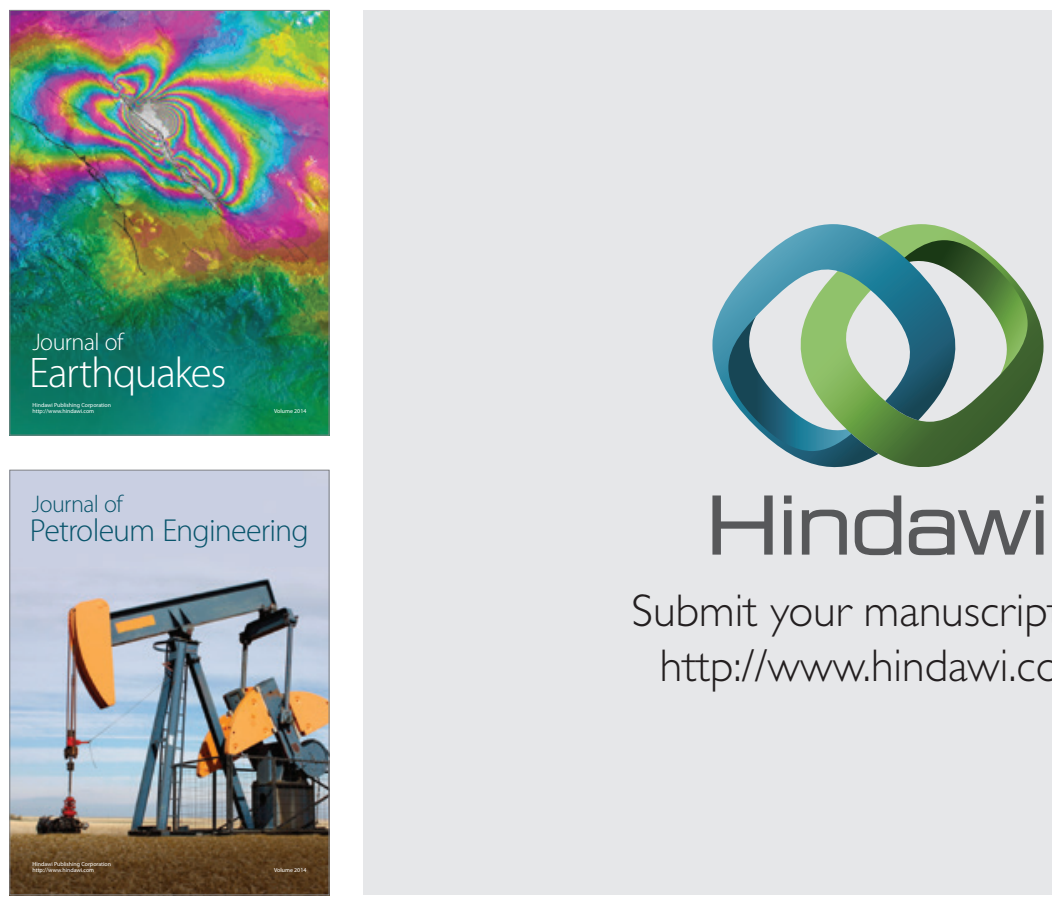

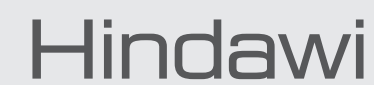

Submit your manuscripts at

http://www.hindawi.com
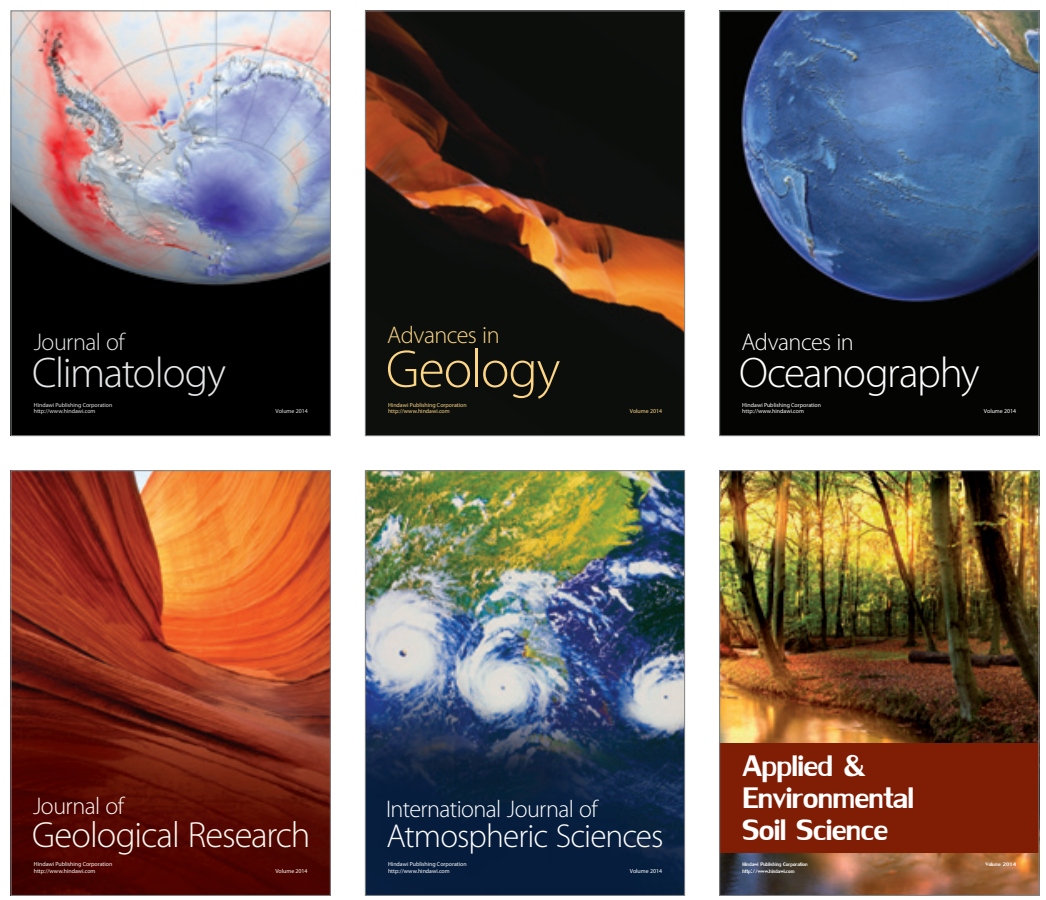
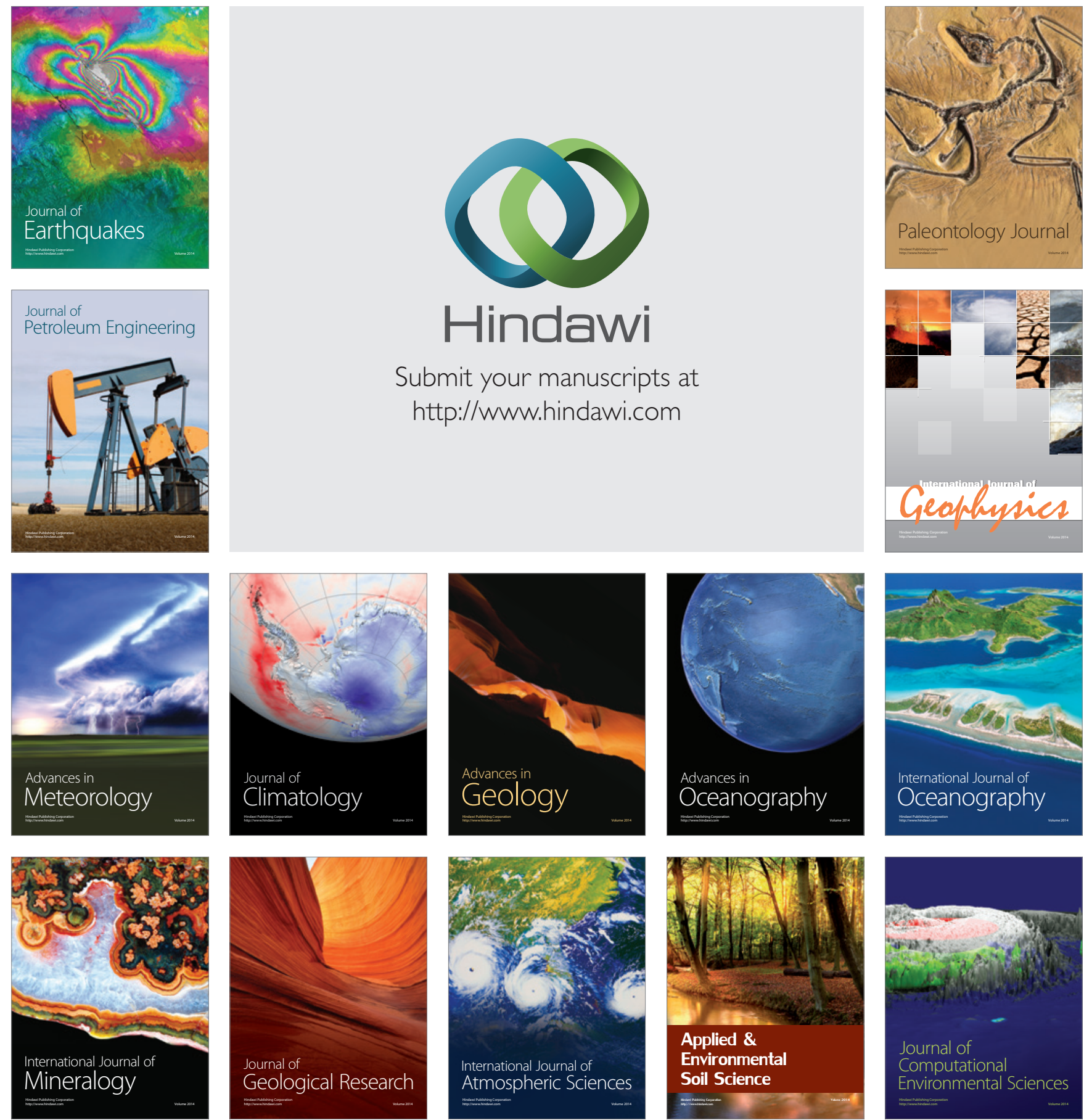